\title{
Synthesis of Renewable Copolyacetals with Tunable Degradation
}

\author{
Bhausaheb S. Rajput, Umesh Chander, Kailash Arole, Florian Stempfle, \\ Shamal Menon, Stefan Mecking, Samir H. Chikkali*
}

Acetal metathesis copolymerization (AMCP) of renewable isohexide diacetals and aliphatic long-chain diacetals is reported and access to a small family of copolyacetals has been established. Crucial 1-2D NMR and MALDI-ToF-MS findings unambiguously confirm the existence of a copolymeric structure. In a stark contrast to the earlier reported isohexide-polyacetals, the current copolyacetals reveal very slow degradation. Hydrolytic degradation of copolyacetal pellets is extremely slow at $\mathrm{pH} 7$, whereas only $30 \%$ degradation over a period of $15 \mathrm{~d}$ is observed in $9 \mathrm{~m}$ hydrochloric acid solution. GPC investigations reveal that with increasing chain-length the rate of degradation reduces, whereas copolyacetals with short-chain aliphatic segments display a faster degradation profile. The reduced rate of degradation can be attributed to the hydrophobic nature of long-chain acetal segments. In situ NMR spectroscopy reveals the existence of formates, hemiacetals, and diols as degradation products. Thus, the rate of degradation can be tuned by the judicious choice of isohexide-diacetal and linear-diacetals in a copolyacetal.

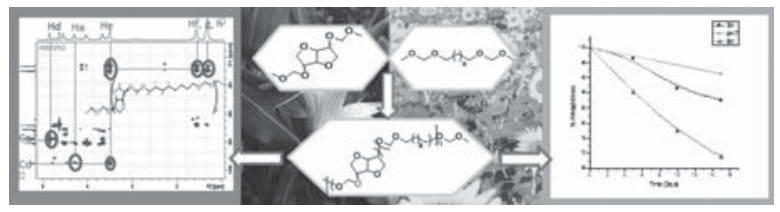

\section{Introduction}

The current polymer industry heavily relies on monomers derived from non-renewable fossil feed-stocks. ${ }^{[1]}$ The ever growing demand for fossil feed-stocks and the consequent depletion of crude oil reserves is driving the scientific community to find better alternatives. ${ }^{[2]}$ It has been unanimously agreed that the use of renewable feed-stocks could be one of the better alternatives. Thus,

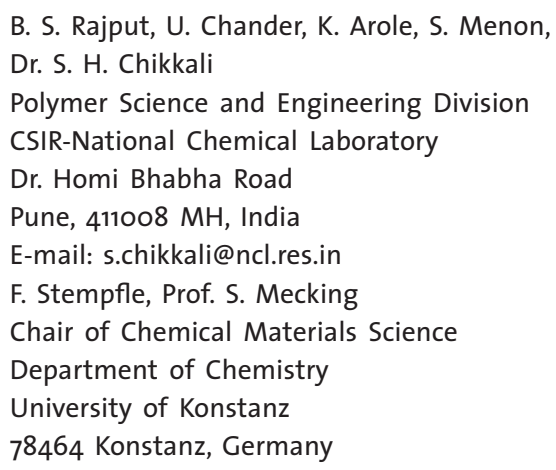

the last decade has seen renewed interest in renewable feed-stocks. ${ }^{[3]}$ The conversion of plant derived sugars and oil to chemicals by various chemical transformations has been intensively investigated. ${ }^{[4]}$ Although the chemical industry is dominated by non-renewable fossil feed-stocks, renewable resource-based products such as poly-lactic acid (PLA), polyhydroxyalkanoates, and sugar cane-based polyethylene have been recently commercialized. ${ }^{[5]}$ PLA is manufactured by NatureWorks. ${ }^{[5 e]}$ Apart from a renewable origin, decomposition of polymeric products without adverse effects on the surrounding environment is another demanding requirement for the next generation of materials. Recent reports indicate that renewable polyacetals meet both the criteria pivotal to the development of futuristic ecofriendly materials (see Figure 1).[6,7] Among renewable resources, starch and carbohydrates are the most abundant and easily accessible biomass feed-stocks and have found numerous applications. ${ }^{[8]}$ These polysaccharides (starch and cellulose) can be readily converted to rigid bicyclic-diols called isohexides. ${ }^{[9-11]}$ Depending on the arrangement of the two hydroxyl groups, isohexides 


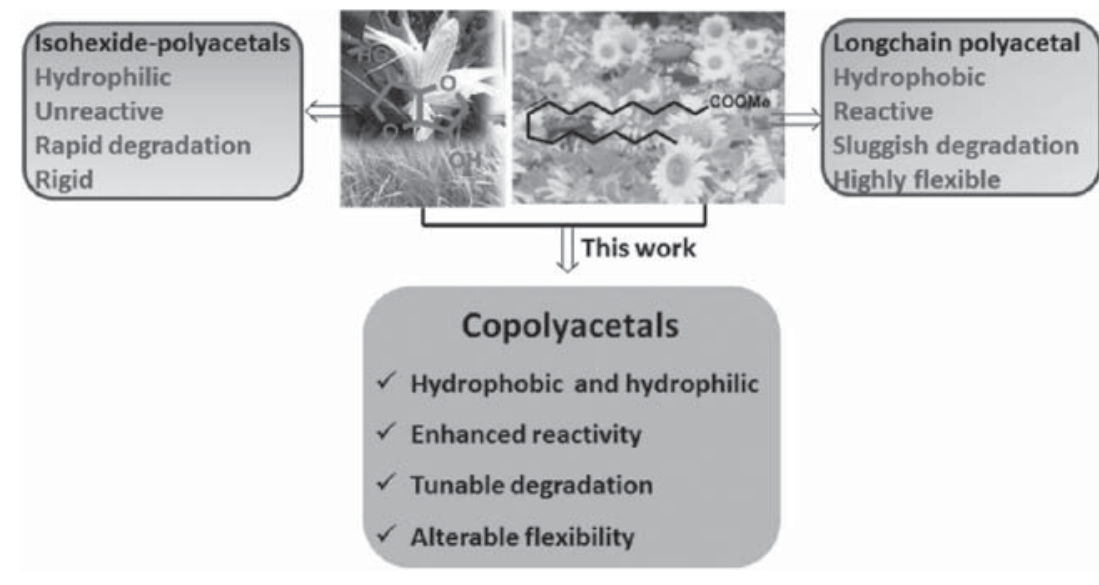

Figure 1. State-of-the-art in renewable polyacetals, and the present work.
However, it was found that the isohexidepolyacetals degraded at a much faster rate than required for most of the anticipated applications of these materials. Hence, there is a need for a new strategy to provide an additional understanding of how to reduce the rate of degradation of these materials or that will allow for tuning of the rate of degradation.

Herein, the synthesis of a small library of fifteen copolyacetals derived from hydrophilic isohexide repeat units and hydrophobic plant oil based long-chain segments is reported (see Figure 1). The impact of varying the number of methylene repeat units are named as isomannide, isosorbide, and isoidide. In isomannide (1,4: 3,6-dianhydromannitol) the two hydroxyl groups on the $\mathrm{C} 2$ and $\mathrm{C} 5$ carbon are in the endo-endo positions, while the unsymmetrical endo-exo isomer is known as isosorbide (1,4: 3,6-dianhydrosorbitol), and the exo-exo isomer as isoidide (1,4: 3,6-dianhydroiditol). ${ }^{[12,13]}$ Isomannide and isosorbide are commercially available and have found various applications in polymer science. The application of isohexides in polymer chemistry has been reviewed in ref. ${ }^{[14]}$ Owing to their chirality and intrinsic rigidity, isohexides have been the subject of exhaustive research in various fields such as catalysis, ${ }^{[15]}$ pharmaceuticals, ${ }^{[16-18]}$ liquid crystalline materials, ${ }^{[7]}$ chiral auxiliary/plasticizers, ${ }^{[19]}$ and polymers. ${ }^{[14]}$ These isohexides are rigid, chiral, and non-toxic molecules that are known to dramatically increase the glass transition temperature $\left(T_{\mathrm{g}}\right)$ when incorporated into a polymer chain. ${ }^{[20]}$ However, direct utilization of isohexides in polymerization requires extreme polymerization conditions and produces dark tarlike polymers. ${ }^{[14]}$ The reduced reactivity of the isohexides can be attributed to two structural features, namely: a) compromised reactivity of the sterically encumbered secondary hydroxyl groups, and b) the inter-intra molecular hydrogen bonding in these motifs. These limitations have been partly addressed by Daan et al. who introduced a "1-carbon extension" strategy. ${ }^{[21]}$ Those monomers with a 1-carbon extension were found to be highly reactive compared to the parent isohexides and various polymers such as polyamides, ${ }^{[22]}$ polyurethanes, ${ }^{[23]}$ polyesters, ${ }^{[24]}$ and co-polyesters ${ }^{[25]}$ have been reported. Thus, significant progress has been made in the synthesis of polymers derived from isohexides; however, degradation of these polymers remains uninvestigated. In our pursuit to address these two issues of reactivity of the isohexides and degradation of the resultant polymers, this group recently reported syntheses of isohexide-diacetals and their corresponding polyacetals. ${ }^{[26]}$ We also demonstrated that the isohexide derived polyacetals degraded under slightly acidic conditions. (chain-length) on the rate of degradation and how the degradation rate can be tuned is investigated.

\section{Results and Discussion}

\subsection{Diacetal and Copolyacetal Synthesis}

The isohexide-diacetals (4a-c) and the long chain diacetals (2a-e) were prepared in moderate yields in a single step synthetic protocol. ${ }^{[27]}$ Treatment of 1,6-hexanediol (1a) and 1,8-octanediol (1b) with dimethoxymethane in the presence of methanesulfonic acid produced diacetals $\mathbf{2} \mathbf{a}$ and $\mathbf{2} \mathbf{b}$ in a good yield (Scheme 1). The existence of isolated monomers $\mathbf{2} \mathbf{a}$ and $\mathbf{2} \mathbf{b}$ was unambiguously ascertained from spectroscopic and analytical data. ${ }^{[28]}$ Typically, ${ }^{1} \mathrm{H}$ NMR spectra of 2a,b displayed a characteristic signal at around $4.6 \mathrm{ppm}$ arising from the methylene protons $\left(\mathrm{OCH}_{2} \mathrm{O}\right)$ and a singlet at $3.3 \mathrm{ppm}$ for the methoxy protons (see Figure S1 and Figure $\mathrm{S} 6$ in the Supporting Information). $\mathrm{A}{ }^{13} \mathrm{C}$ NMR resonance at $96 \mathrm{ppm}\left(\mathrm{OCH}_{2} \mathrm{O}\right)$ further confirmed the formation of the acetal moiety and the resonance at $55 \mathrm{ppm}$ could be ascribed to the terminal methoxy $\left(\mathrm{OCH}_{3}\right)$ carbon (see Figure S2 and Figure S7 in the Supporting Information). The existence of the diacetals $\mathbf{2} \mathbf{a}, \mathbf{b}$ was further corroborated by a characteristic electrospray ionization mass spectroscopy (+ve) signal at $m / z=229.14[\mathrm{M}+\mathrm{Na}]^{+}$for $2 \mathrm{a}$ and $m / z=257.17[\mathrm{M}+\mathrm{Na}]^{+}$for $\mathbf{2 b}$ (see Figure S5 and S10 in the Supporting Information). The isohexide-diacetals 4a-c and long chain diacetals $2 \mathrm{a}$-e were subjected to acetal metathesis copolymerization (AMCP) (the term AMCP is similar to ADMET polymerization). A small library of 15-copolyacetals was prepared by varying the isohexidediacetals (4a-c) and the methylene sequence of the linear-diacetals (2a-e). Typical copolymerization conditions included heating the monomers from 60 to $90{ }^{\circ} \mathrm{C}$ in a $50 \mathrm{~mL}$ Schlenk tube equipped with an overhead stirrer and vacuum connection. 


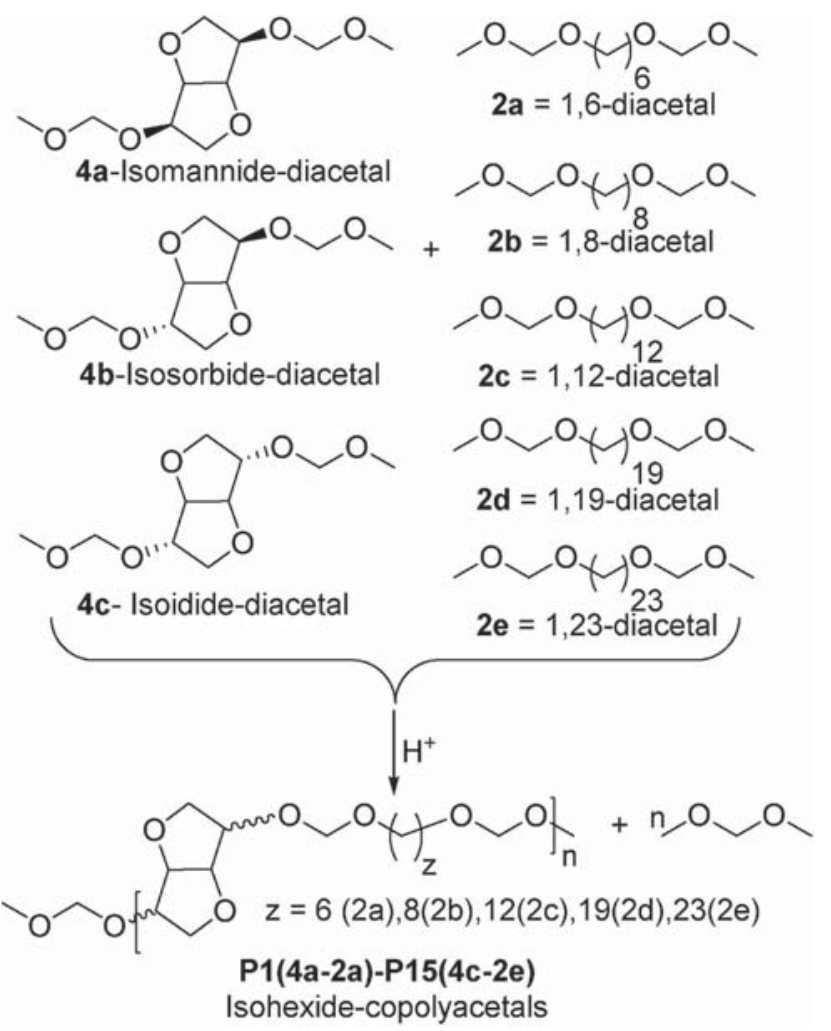

Scheme 1. Synthesis of copolyacetals $\mathrm{P}_{1}(\mathbf{4 a - 2 a})-\mathrm{P}_{15}(\mathbf{4 C - 2 e})$ by AMCP.
The copolymerization was initiated by adding a suitable amount of catalyst ( $p$-toluenesulfonic acid) and the by-product (dimethoxymethane) was continuously expelled by vacuum-argon-purge cycles. Here, the evaporation of short-chain diacetal monomers must be taken in to account while applying the vacuum and should be minimized. After polymerization, the resultant highly viscous material was cooled to room temperature. The obtained solid was dissolved in chloroform, and was precipitated from methanol to give the desired copolyacetals P1(4a-2a)-P15(4c-2e) as white solids in low to excellent yields (20-80\%). However, some copolyacetals (isohexide-diacetals with short-chain 1,6-diacetal and 1,8-diacetal; see Table 1) could not be precipitated out as they were found to be present in the liquid state. The low yields for P1(4a-2a) indicated monomer evaporation or a stoichiometric imbalance in the reaction system. The copolyacetals were rigorously characterized and Table 1 summarizes the most significant findings.

\subsection{Copolyacetal of Isomannide-Diacetal (4a) and Linear Diacetals (2a-e)}

AMCP was carried out as described above and the resultant copolyacetals were characterized using a combination of spectroscopic and analytical methods. The formation of copolyacetal $\mathbf{P 2}(\mathbf{4 a - 2 b})$ was attested by the reduced

Table 1. Isohexide derived copolyacetals and their properties. Refer to the Experimental Section for detailed polymerization conditions. $\mathrm{ND}=$ end groups could not be detected, hence absolute molecular weight could not be determined. NO = not observed due to liquid samples.

\begin{tabular}{lccccccc}
\hline Run & Monomers & Polymers & $\overline{\boldsymbol{M}}_{\mathbf{n}}{ }^{\text {a) }}$ & $\overline{\boldsymbol{M}}_{\mathbf{w}}^{\text {b) }}$ & PDI $^{\text {b) }}$ & $\boldsymbol{T}_{\mathbf{m}}$ & Yield \\
\hline 1 & 4a:2a & P1(4a-2a) & ND & 10.7 & 1.7 & NO & 20 \\
2 & 4a:2b & P2(4a-2b) & ND & 4.9 & 1.9 & 45,118 & 41 \\
3c) & 4a:2c & P3(4a-2c) & 12.3 & 8.0 & 1.8 & 49,61 & 48 \\
4 & 4a:2d & P4(4a-2d) & ND & 3.4 & 1.8 & 53,77 & 50 \\
5 & 4a:2e & P5(4a-2e) & ND & 6.5 & 2.8 & 52,75 & 64 \\
6 & 4b:2a & P6(4b-2a) & ND & 3.9 & 2.2 & NO & 59 \\
7 & 4b:2b & P7(4b-2b) & ND & 4.5 & 2.5 & NO & 43 \\
8 & 4b:2c & P8(4b-2c) & 11.9 & 4.2 & 2.2 & 57 & 65 \\
9 & 4b:2d & P9(4b-2d) & ND & 5.1 & 2.5 & 53,75 & 73 \\
10 & 4b:2e & P10(4b-2e) & ND & 3.9 & 2.4 & 54,75 & 66 \\
11 & 4c:2a & P11(4c-2a) & 9.5 & 2.0 & 1.9 & NO & 80 \\
12 & 4c:2b & P12(4c-2b) & 8.0 & 3.8 & 2.1 & NO & 57 \\
13 & 4c:2c & P13(4c-2c) & ND & 4.8 & 3.1 & 55 & 64 \\
14 & 4c:2d & P14(4c-2d) & ND & 4.9 & 2.0 & 68 & 66
\end{tabular}

a) $\bar{M}_{\mathrm{n}}$ (into $10^{3}$ ) determined by NMR in $\mathrm{g} \mathrm{mol}^{-1}$; b) $\bar{M}_{\mathrm{w}}$ (into $10^{3}$ ) and the polydispersity index (PDI) were obtained from GPC in chloroform solvent at room temperature with respect to polystyrene standards; ${ }^{\mathrm{c}}$ Polymerization was carried out at $60-110^{\circ} \mathrm{C}$ under a vacuum. 


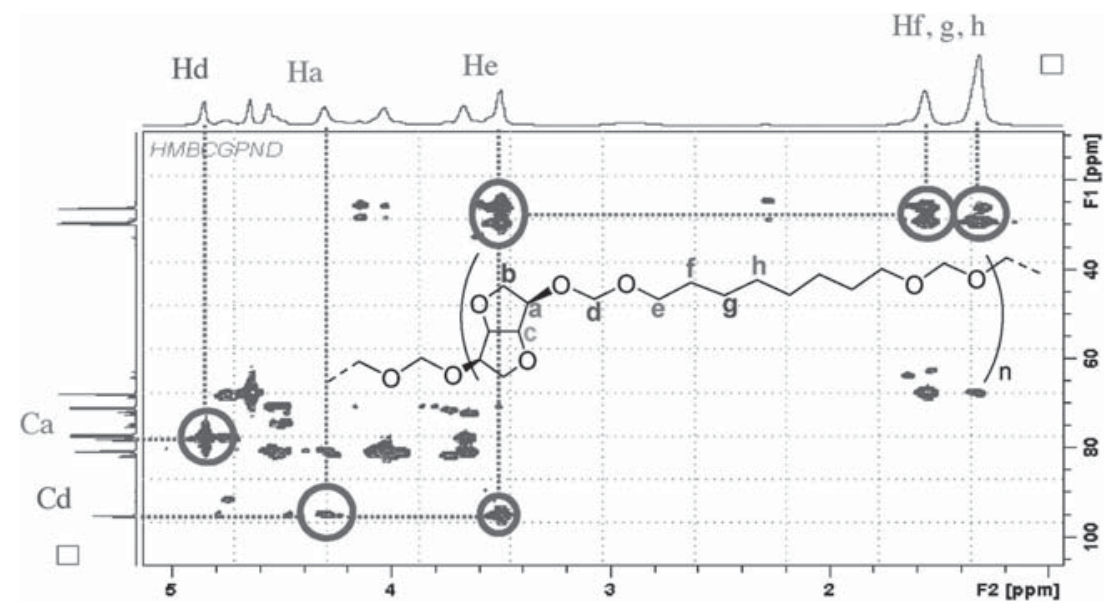

Figure 2. ' $\mathrm{H}-{ }^{13} \mathrm{C}(\mathrm{HMBC})$ spectrum of $\mathrm{P}_{2}(\mathbf{4 a - 2 b})$ in $\mathrm{CDCl}_{3}(500 \mathrm{MHz}, 298 \mathrm{~K})$.

(f, g, h, etc. carbons) in the range of 25-30 ppm. The $\mathrm{HMBC}$ experimental findings were further strengthened by a NOESY experiment. In a typical NOESY experiment, the 4.7-4.6 ppm (d-protons) protons displayed cross peaks to 4.2 and 3.5 ppm protons (see Figure S15 in the Supporting Information). Thus, the above NMR experiments unambiguously prove the existence of anticipated copolyacetal and demonstrate through bond correlation between "a-d-e" type protons and carbons. End group analysis of P3(4a-2c) by ${ }^{1} \mathrm{H}$ NMR spectroscopy revealed a number average molecular weight $\left(\bar{M}_{n}\right)$ of $12300 \mathrm{~g} \mathrm{~mol}^{-1}$. However, detection of end groups by NMR was difficult in

intensity of a proton resonance at 3.3 and 4.6-4.7 ppm and the absence of a ${ }^{13} \mathrm{C}$ peak at $55 \mathrm{ppm}$ (corresponding to the terminal $-\mathrm{OCH}_{3}$ group (see Figure S13 and Figure S14 in the Supporting Information). The ratio between the eight backbone protons of $4 \mathrm{a}(2: 2: 2: 2)$ and the sixteen backbone protons of $\mathbf{2} \mathbf{b}$ was retained in $\mathbf{P} \mathbf{2}(\mathbf{4 a - 2} \mathbf{b})$. The splitting pattern of the polymer backbone protons is similar to that of $\mathbf{4 a}$ protons, suggesting that the stereochemistry of monomer $4 \mathrm{a}$ is most likely preserved during the polymerization. These typical features were associated with all other copolyacetals derived from isosorbide and isoidide. These assignments were further corroborated by 2D NMR findings. In a decisive long-range through bond $\mathrm{C}-\mathrm{H}$ correlation experiment $(\mathrm{HMBC})$, an acetal carbon (Figure 2, "d" carbon) at 95 ppm revealed through bond correlation to protons at 4.2 ("a" proton that originates from the isomannide backbone) and $3.5 \mathrm{ppm}$ ("e" protons from the long-chain aliphatic segment). The 3.5 ppm "e" protons further displayed cross peaks to methylene carbons the majority of the copolyacetals and hampered absolute molecular weight determination. Gel permeation chromatography (GPC) investigation of the copolyacetals revealed increased molecular weight when compared to previously reported parent isohexide-diacetal homopolymers. The enhancement in molecular weight can be ascribed to the increased reactivity of linear diacetals (see Table 1). Note that GPC data was recorded with polystyrene standards (to calculate $\bar{M}_{\mathrm{w}}$ ), which is apparently not a very suitable standard for this type of polymer. The copolyacetal P2(4a2b) was subjected to MALDI-ToF-MS analysis in order to determine the molar mass and repeat unit mass. It should be noted that different copolymers, such as alternating, random, block, or graft, can potentially generate different and probably more complex fragmentation patterns which cannot be clearly distinguished.

A representative spectrum of $\mathbf{P} \mathbf{2}(\mathbf{4 a - 2} \mathbf{b})$ is displayed in Figure 3. A typical MALDI-ToF-MS spectrum revealed a set of MS signals, each with a mass interval of $316 \mathrm{Da}$, which

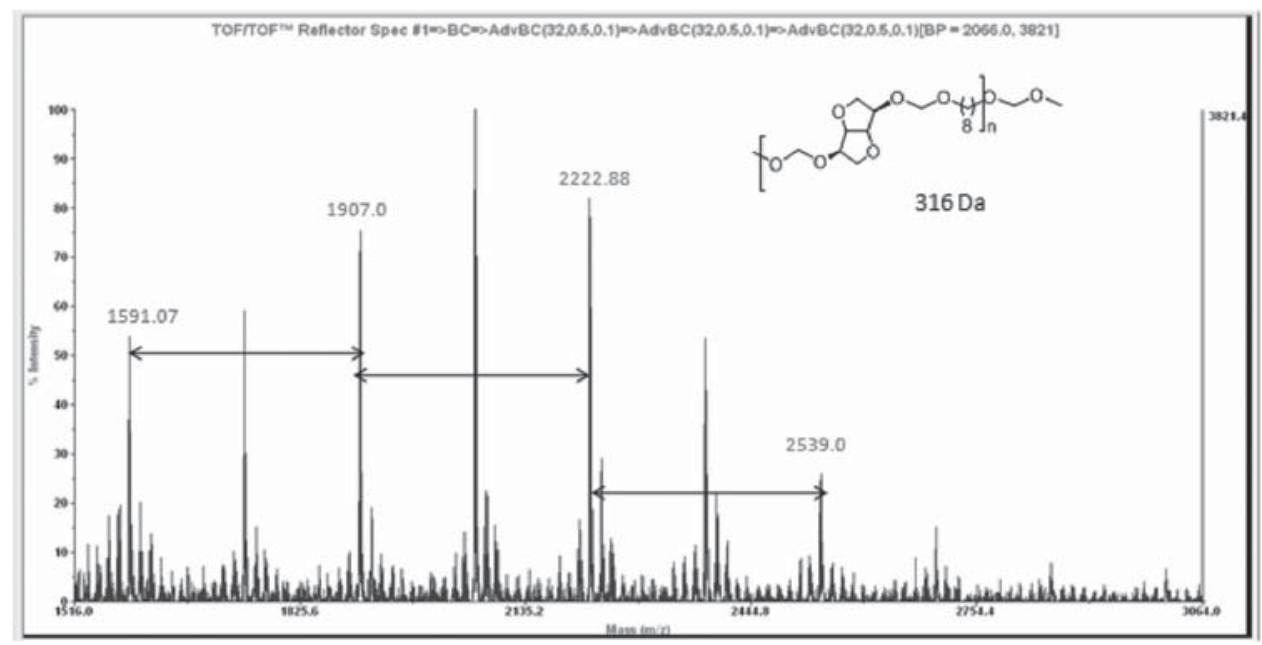

Figure 3. MALDI-ToF-MS spectrum of $\mathbf{P} \mathbf{2}(\mathbf{4 a - 2 b})$ recorded in dithranol. 


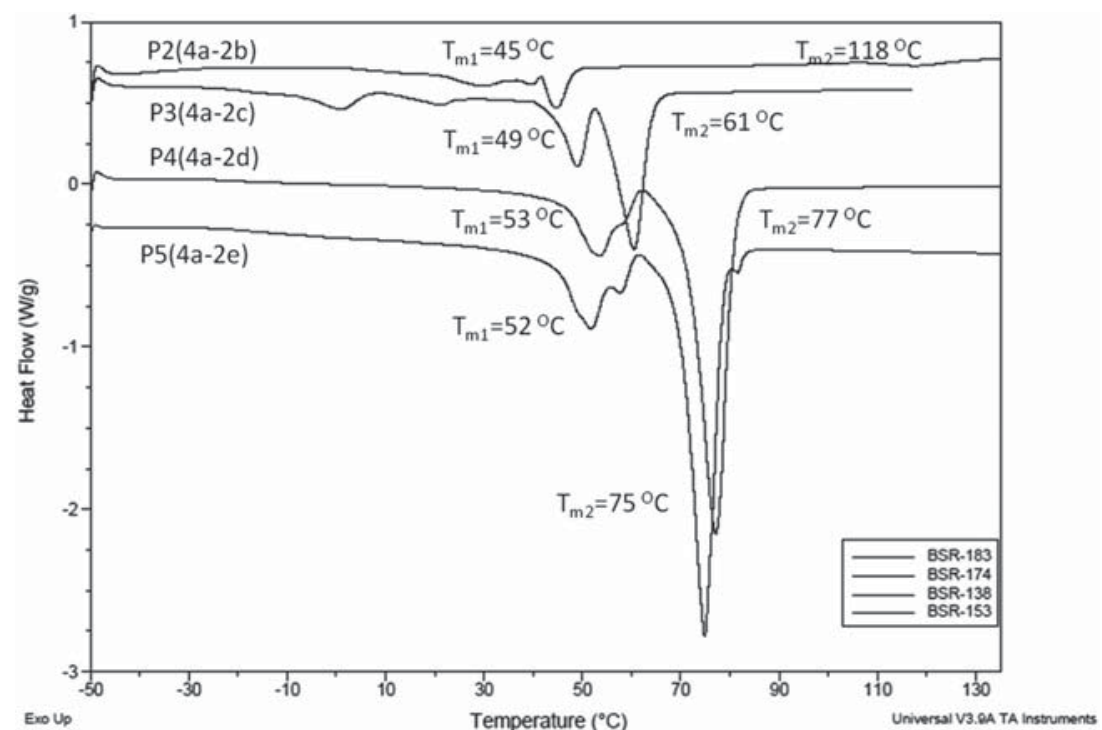

Figure 4. DSC heating curves of isomannide-copolyacetals under $\mathrm{N}_{2}$ atmosphere (data from second heating except IMD+1,8 [1 ${ }^{\text {st }}$ heating]). could be observed for $\mathbf{P 4}(\mathbf{4 a - 2 d )}$ and P5(4a-2e). The thermal stability of copolyacetals was determined using TGA between 0 to $600{ }^{\circ} \mathrm{C}$ in a nitrogen atmosphere (see Figure 5). The copolyacetals P2(4a-2b) and P3(4a-2c) started decomposing at around $150{ }^{\circ} \mathrm{C}$ and maximum decomposition (>50\%) was observed around $300{ }^{\circ} \mathrm{C}$. By comparison, the longchain derived copolyacetals P4(4a-2d) and P5(4a-2e) were found to be thermally stable up to $325^{\circ} \mathrm{C}$ with only less than $15 \%$ weight loss. Furthermore, the maximum weight loss (about 80\%) in these cases [P4(4a-2d) and P5(4a-2e)] was observed at $400{ }^{\circ} \mathrm{C}$. The above observations suggest that the stability of the copolyacetals increases with increasing chain-length of the aliphatic long-chain diacetal monomers. exactly matches with the molar mass of the copolymer repeat unit (along with repeat unit mass for $4 \mathrm{a}=158 \mathrm{Da}$ and $\mathbf{2 b}=158 \mathrm{Da}$ ). However, since both the repeat units in this copolymer have the same molar mass (158 Da), MALDIToF-MS data was collected for P3(4a-2c). As anticipated, a repeat unit mass of $372 \mathrm{Da}$ was observed, confirming the molar mass of the repeat unit (see Figure S20 in the Supporting Information), though the end-groups could not be accurately determined. After having fully established the structural characteristics of the copolyacetals, attention was turned towards the thermal behaviour of the copolyacetals. The thermal behaviour of the copolyacetals was investigated by differential scanning calorimetry (DSC) and thermogravimetric analysis (TGA). The majority of the copolyacetals displayed at least two melting transitions, suggesting the formation different types of copolyacetals (see Figure 4). Compared to the parent isohexide polyacetals, the copolyacetals were found to melt at lower temperatures. The reduction in melting temperature $\left(T_{\mathrm{m}}\right)$ of the copolyacetal can be attributed to the incorporation of flexible segments in the form of linear-diacetals. Typically, the melting temperature of the copolyacetals was found to increase with increasing chain-length of the linear-diacetals. For instance, P3(4a-2c) with a 12-carbon chain length displayed a $T_{\mathrm{m} 2}$ of $61^{\circ} \mathrm{C}$; whereas $\mathbf{P 4}(\mathbf{4 a - 2 d})$ with a 19-carbon chain length displayed a $T_{\mathrm{m} 2}$ of $77^{\circ} \mathrm{C}$. However, no significant difference

\subsection{Copolyacetal of Isosorbide/Isoidide-Diacetal (4b/4c) and Linear Diacetals (2a-e)}

The isosorbide (4b) and isoidide (4c) derived copolyacetals were prepared as reported in the general copolymerization section and Table 1 summarizes the significant properties of the resultant copolyacetals [P6(4b-2a)-P15(4c-2e)]. The proton and carbon NMR investigations revealed formation of the anticipated copolyacetals. The appearance of isosorbide backbone protons in the ratio 1:3:2:1:1 (Figure S28 in the Supporting Information) suggested that the stereochemistry of monomer $\mathbf{4 b}$ is most likely retained

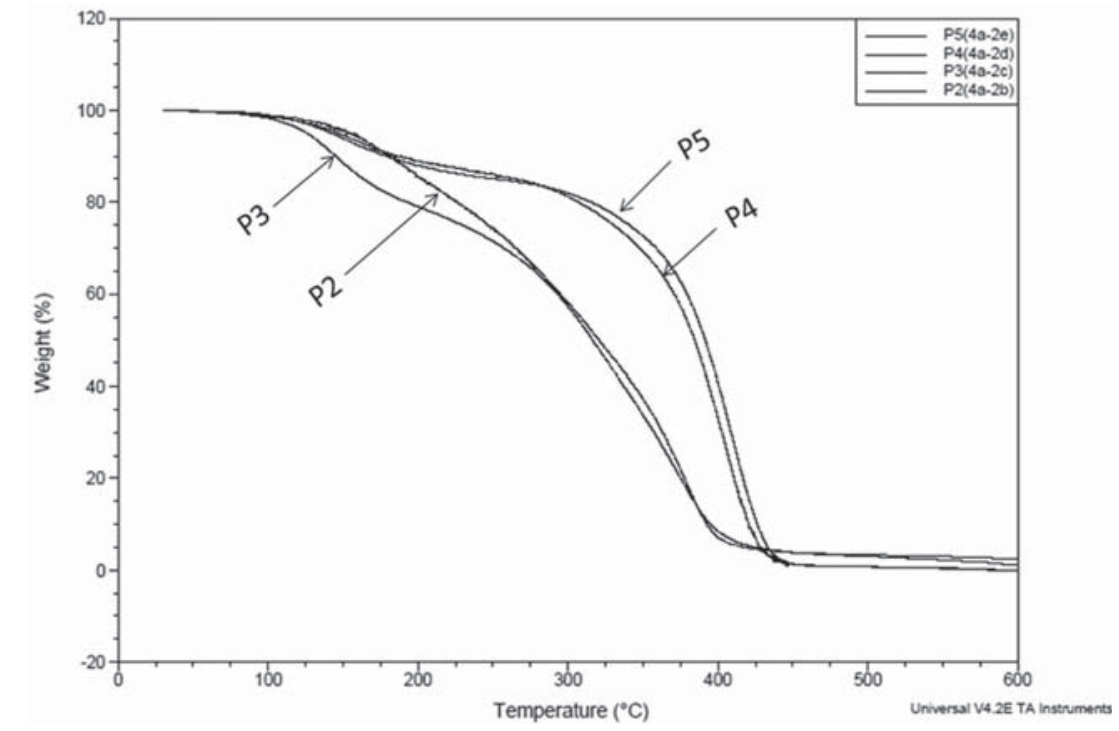

Figure 5. TGA traces of isomannide-copolyacetals $\mathbf{P}_{\mathbf{2}}(\mathbf{4 a - 2 b})$ to $\mathbf{P}_{5}(\mathbf{4 a - 2 e})$ recorded between $0-600{ }^{\circ} \mathrm{C}$ in a nitrogen atmosphere. 
during the polymerization (see Figure S30, Figure S33, Figure S36, and Figure S40 in the Supporting Information). ${ }^{13} \mathrm{C}$ NMR revealed the absence of the $55 \mathrm{ppm}$ signal confirming the formation of high molecular weight copolyacetal P7(4b-2b) (see Figure S31 in the Supporting Information). Multinuclear NMR spectroscopy (1-2D) established the formation of P10(4b-2e) (see Figure S42 and Figure S43 in the Supporting Information). The isosorbide derived copolyacetals were further analyzed by MALDIToF-MS. A typical MALDI-ToF-MS spectrum of copolyacetal P9(4b-2d) (run 9) revealed three sets of MS signals along with molar mass of $470 \mathrm{Da}$, which exactly coincides with the theoretical molar mass of the repeat unit of [P9(4b-2d)] (see Figure S38 in the Supporting Information). The three sets of signals might originate from copolyacetals with different chain-ends. The thermal transitions for the above copolyacetals were recorded by DSC and thermal stability was evaluated using TGA. The short-chain copolyacetals P6(4b-2a) and P7(4b-2b) were found to be in the liquid state at room temperature, indicating that the $T_{\mathrm{m}}$ is lower than room temperature. Differently, the long-chain derived copolyacetal [P8(4b-2c)-P10(4b-2e)] were isolated as solids with similar $T_{\mathrm{m}} \mathrm{s}$ (Table 1, run 8, 9, and 10; see Figure S45 in the Supporting Information). The short chain copolyacetals [P8(4b-2c)] displayed about $60 \%$ weight loss below $300{ }^{\circ} \mathrm{C}$, whereas only $20 \%$ weight loss was observed in the case of long chain copolyacetals [P9(4b-2d)] and [P10(4b-2e)] (see Figure S46 in the Supporting Information).

Similarly, isoidide-diacetal derived copolyacetals and their properties are listed in Table 1 . The resultant copolyacetals were precipitated from a chloroform:methanol mixture to obtain the desired copolyacetals in excellent isolated yields. The detailed polymerization conditions are reported in Table 2 (see Experimental Section). The copolyacetals P11(4c-2a) to P15(4c-2e) were analyzed using a combination of spectroscopic and analytical methods. 1-2D NMR studies revealed the formation of high molecular weight copolyacetals [P11(4c-2a) $=9500 \mathrm{~g} \mathrm{~mol}^{-1} ; \mathbf{P 1 2}(\mathbf{4 c - 2 b})=8000 \mathrm{~g} \mathrm{~mol}^{-1}$ ], with retention of configuration at the isoidide-diacetal repeat unit (see Figure S47, Figure S50, Figure S53, Figure S58, and Figure S60 in the Supporting Information). The 2D NMR of P13(4c-2c) further confirmed the formation of copolymer (see Figure S55 and Figure S56 in the Supporting Information). The NMR observations were corroborated by GPC measurements that displayed weight average molecular weight in the range of 2000-10 $700 \mathrm{~g} \mathrm{~mol}^{-1}$.29] MALDIToF-MS analysis of the copolyacetals P11(4c-2a) displayed a repeat unit mass of $288 \mathrm{Da}$, which is consistent with the theoretical molar mass of the copolyacetal repeat unit. However, the spectrum was more complex due to the likely presence of various types of copolymers (block, random, alternating, graft etc.) and chain-ends (see Figure S48 in the Supporting Information).

The thermal behavior of these copolyacetals was monitored by DSC and TGA. Copolyacetals with a 1:1 comonomer ratio displayed a single melting transition (runs 13,14 , and 15) that lay in between the $T_{m}$ of the two homopolymers (see Figure S62 in the Supporting Information). The isoidide-C12 derived copolyacetal [P13(4c-2c)] displayed about $50 \%$ weight loss around $300{ }^{\circ} \mathrm{C}$, whereas, only $15 \%$ weight loss was observed in the case of long

Table 2. Copolymerization of isohexide-diacetals (4a-c) with linear diacetals (2a-e).

\begin{tabular}{|c|c|c|c|c|}
\hline Copolyacetal & $4 \mathrm{a}-\mathrm{c}\left[\mathrm{g},\left(\times 10^{-3} \mathrm{~mol}\right)\right]$ & 2a-e $\left[\mathrm{g},\left(\times 10^{-3} \mathrm{~mol}\right)\right]$ & $p$-TSA $\left[\times 10^{-3} \mathrm{~mol}\right]$ & Time [h] \\
\hline P1(4a-2a) & $1.0(4.27)$ & $0.88(4.27)$ & 0.42 & 12 \\
\hline P2(4a-2b) & $1.0(4.27)$ & $0.99(4.27)$ & 0.42 & 6 \\
\hline P3(4a-2c) & $1.0(4.27)$ & $1.24(4.27)$ & 0.42 & 12 \\
\hline$P 4(4 a-2 d)$ & $0.20(0.89)$ & $0.34(0.89)$ & 0.089 & 12 \\
\hline P5(4a-2e) & $0.5(2.13)$ & $0.95(2.13)$ & 0.213 & 12 \\
\hline P6(4b-2a) & $0.71(2.99)$ & $0.61(2.99)$ & 0.29 & 12 \\
\hline P7(4b-2b) & $1.0(4.27)$ & $1.0(4.27)$ & 0.42 & 12 \\
\hline$P 8(4 b-2 c)$ & $1.0(4.27)$ & $1.24(4.27)$ & 0.21 & 12 \\
\hline$P 9(4 b-2 d)$ & $0.80(2.57)$ & $0.48(2.57)$ & 0.20 & 12 \\
\hline$P 10(4 b-2 e)$ & $0.5(2.13)$ & $0.95(2.13)$ & 0.21 & 12 \\
\hline P11(4c-2a) & $0.70(2.99)$ & $0.61(2.99)$ & 0.29 & 12 \\
\hline $\mathrm{P} 12(4 \mathrm{c}-2 \mathrm{~b})$ & $0.94(4.02)$ & $0.94(4.02)$ & 0.40 & 12 \\
\hline $\mathrm{P} 13(4 \mathrm{c}-2 \mathrm{c})$ & $0.88(3.76)$ & $1.09(3.76)$ & 0.37 & 12 \\
\hline P14(4c-2d) & $0.58(2.47)$ & $0.95(2.47)$ & 0.24 & 12 \\
\hline $\mathrm{P} 15(4 c-2 e)$ & $0.5(2.13)$ & $0.94(2.13)$ & 0.21 & 12 \\
\hline
\end{tabular}


chain copolyacetals [P14(4c-2d)] and [P15(4c-2e)] (see Figure S63 in the Supporting Information).

\subsection{Degradation of Copolyacetals}

The fate of next generation of polymeric materials for some niche applications will heavily rely on two decisive parameters: a) the origin (renewable or non-renewable) of the material, and b) environmental compatibility. Although significant progress has been made in terms of renewable monomers and polymers, very little information exists on the degradation of the majority of polymeric materials. In this context, the acetal $\left(-\mathrm{OCH}_{2} \mathrm{O}-\right)$ link has been found to be very sensitive to acidic environments and is primarily responsible for the degradation of polyacetals in acidic media. ${ }^{[30,31]}$ In our previous investigation, it was reported that long chain polyacetals degrade very slowly, while isohexide-polyacetals were found to degrade rapidly within minutes. ${ }^{[26]}$ Given these reports, it was anticipated that varying the chain-length of linear long-chain diacetal monomers would allow tuning of the degradation rate of the resultant copolyacetals. The copolyacetals were subjected to acid induced degradation and their degradation behavior was investigated by: 1) GPC; 2) solid-state degradation; and 3) NMR investigations and column chromatographic isolation of degradation products.

\subsection{Monitoring Acid Induced Degradation by GPC}

The acid induced degradation of copolyacetal [P8(4b-2c)] was monitored by gel permeation chromatography (GPC). A suitable amount of isosorbide derived-copolyacetal [P8(4b-2c)] was dissolved in chloroform, $1 \mathrm{M} \mathrm{HCl}$ (in dioxane) was added and the resultant mixture was stored for 20,40, and $60 \mathrm{~min}$. The volatiles were evaporated to obtain solid material, which was dissolved in chloroform and GPC was carried out. A similar protocol was followed for P3(4a-2c), P5(4a-2e), P10(4b-2e), P13(4c-2c), and P15(4c-2e). The relatively short chain (C12) copolyacetal $[\mathbf{P 8}(\mathbf{4 b - 2 c})]$ was found to degrade to low molecular weight fragments within $20 \mathrm{~min}$, whereas the long-chain diacetal (C23) derived copolyacetal $[\mathrm{P} 10(4 \mathrm{~b}-2 \mathrm{e})]$ required at least $1 \mathrm{~h}$ to degrade to similar low molecular weight fragments (Figure 6). A similar protocol was followed to investigate the degradation of isomannide and isoidide derived copolyacetals.

The short chain isoidide based copolyacetal P13(4c-2c) degraded at much faster rates (slope of the line) than the corresponding long-chain copolyacetal P15(4c-2e) (see Figure S65 in the Supporting Information). Almost the same trend was observed for the isomannide-short (C12) chain copolyacetal P3(4a-2c) and P5(4a-2e) (see Figure S64 in the Supporting Information), although slight deviation was noted in case of P5(4a-2e). These observations clearly demonstrated that incorporation of long-chain diacetals

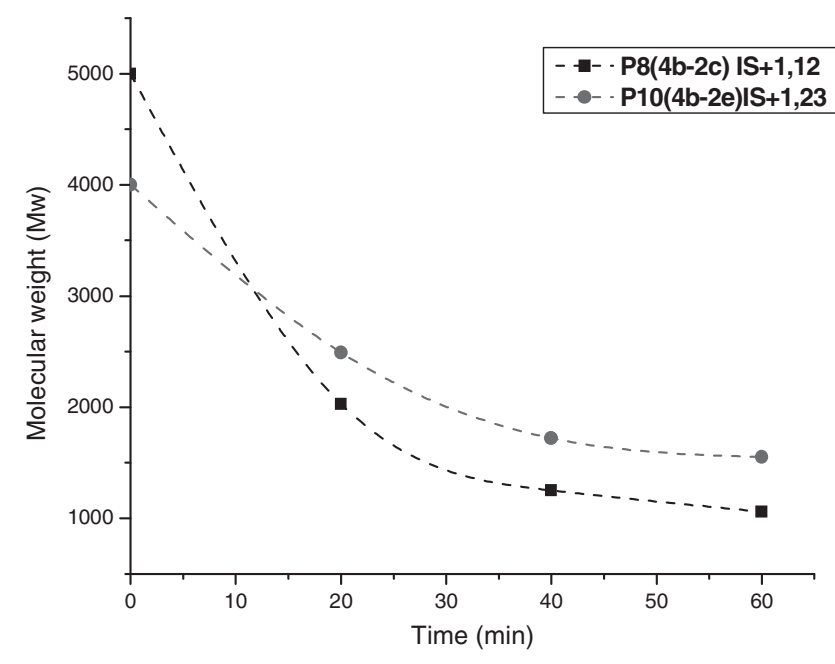

Figure 6. Monitoring the degradation of copolyacetals P8(4b-2c) and P1o (4b-2e) using GPC.

into the copolyacetals significantly retarded the rate of degradation compared to the previously reported parent isohexide-polyacetals.

\subsection{Solid-State Hydrolytic Degradation of Copolyacetal}

The above GPC investigations dealt with liquid samples and the degradation behavior of copolyacetals in the solution state. In our efforts to investigate the solid-state behavior of the copolyacetals, solid samples were prepared and subjected to hydrolytic degradation. Hydrolytic degradation of the C23 polyacetal-homopolymer in $3 \mathrm{MHCl}$ has been recently reported, see ref. ${ }^{[32]}$ The isoidide-derived long-chain copolyacetal P15(4c-2e) was chosen as a representative copolyacetal for these investigations. Compact pellets (see Figure 7) of identical dimensions were prepared from the polymer melt. Typically, the pellets were suspended in solution for a defined period of time, the solution was decanted after the specific interval, and the pellet was dried under vacuum until constant weight was obtained. Next, the same pellet was suspended in a fresh solution for a defined time and the above procedure was repeated for a desired number of times, or as in Table 4. Suspending the pellet in $\mathrm{pH} 7$ solution for $15 \mathrm{~d}$ led to minor (only $7 \%$; the average of two experiments) weight loss (see

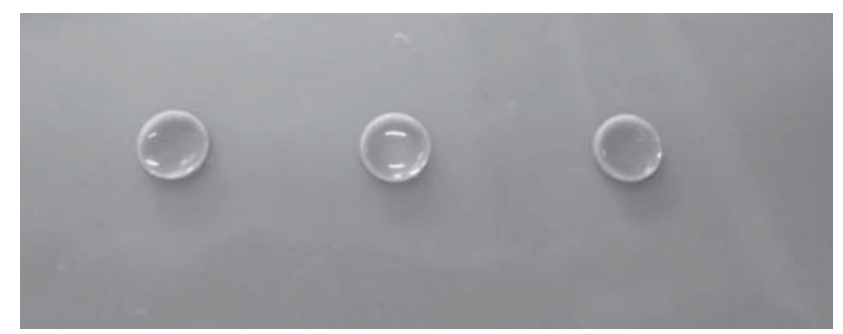

Figure 7. Pellets obtained from copolyacetal P15(4c-2e). 


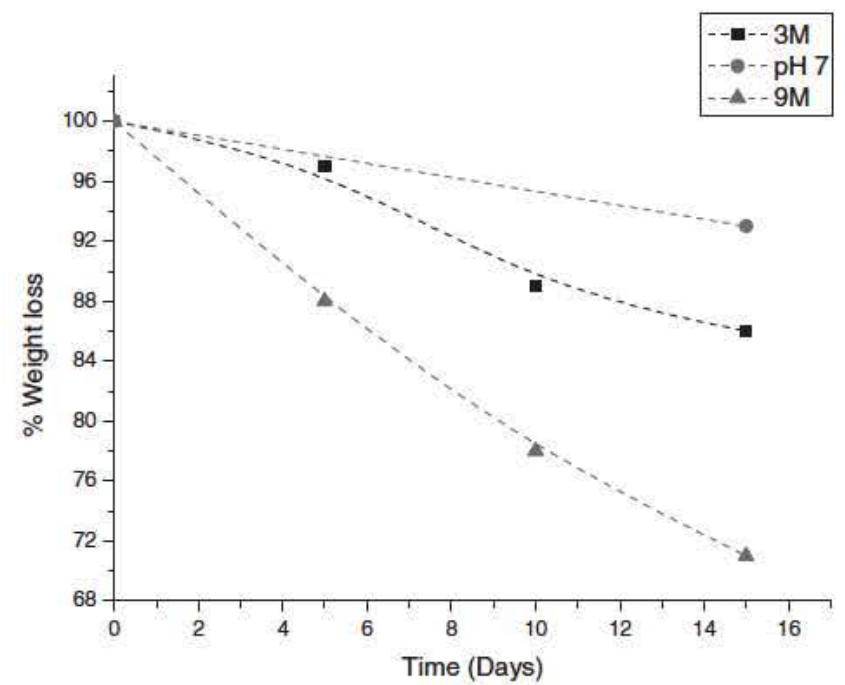

Figure 8. Hydrolytic degradation of pellets derived from $P_{15}(4 c-2 e)$.

Figure 8). This lethargic weight loss can be attributed to the presence of hydrophobic long-chain diacetal 2e (1,23-diacetal) segments in the copolyacetal P15(4c-2e). Unlike at physiological $\mathrm{pH}$, considerable weight loss was observed when pellets were exposed to acidic solutions ( $3 \mathrm{M}$ and $9 \mathrm{M}$ $\mathrm{HCl}$ ) for periods of 5,10 , and $15 \mathrm{~d}$ (see Figure 8). Thus, exposure of $\mathrm{P} 15(4 \mathrm{c}-2 \mathrm{e}$ ) to $3 \mathrm{M} \mathrm{HCl}$ for $5 \mathrm{~d}$ led to $3 \%$ weight loss, while higher weight loss (12\%) was observed in $9 \mathrm{M}$ hydrochloric acid solution. Monitoring the weight loss over $15 \mathrm{~d}$ revealed a total weight loss of $15 \%$ in $3 \mathrm{M} \mathrm{HCl}$, while almost double weight loss $(30 \%)$ was observed in $9 \mathrm{M} \mathrm{HCl}$ solution. Also, the rate of weight loss was higher for the first $10 \mathrm{~d}$, while the next $5 \mathrm{~d}$ revealed a reduced rate of weight loss. This is most likely due to the deposition of degraded material over the pellet surface which by now (after $10 \mathrm{~d}$ ) is not directly exposed to the acidic media and therefore no longer available for further degradation. These observations clearly demonstrate that the incorporation of hydrophobic long-chain diacetals (such as 1,23-diacetal) significantly decreases the degradation rate and the rate of degradation can be tuned by varying the composition of the two monomers. Thus, the present strategy provides an additional handle to tune the rate of degradation that is very crucial for end use applications. ${ }^{[33]}$

\subsection{Monitoring Acid Induced Degradation by NMR and Isolation of Degradation Products}

The GPC and solid state (hydrolytic degradation) studies allowed us to conclude that the copolyacetals degrade in acidic media. However, the nature of the degradation products remained unclear at this point. In an attempt to shed light on this issue, degradation behavior was tracked using NMR spectroscopy and the isolation of degrada- tion products was attempted. In an NMR tube experiment, $55 \mathrm{mg}$ of P3(4a-2c) was dissolved in $0.6 \mathrm{~mL}$ of $\mathrm{CDCl}_{3}$ and $0.1 \mathrm{~mL}$ of methanesulfonic acid (MSA) was added to this solution. A time resolved proton NMR spectrum of $\mathrm{P3}(4 \mathrm{a}-2 \mathrm{c})$ after the addition of MSA is depicted in Figure S67 in the Supporting Information. The intensity of $-\mathrm{OCH}_{2} \mathrm{O}$ - proton resonance at 4.6 and $4.8 \mathrm{ppm}$ decreased, suggesting that the acetal moiety was splitting or the copolyacetal was degrading to smaller fragments. Almost simultaneously, new peaks at 4.7, 4.9, and $5.1 \mathrm{ppm}$ started appearing, which can be assigned to various methylene protons originating from $-\mathrm{ROCH}_{2} \mathrm{OH}$ type fragments (see Figure $\mathrm{S} 68$ in the Supporting Information). Along the same line, the resonance at $3.5 \mathrm{ppm}$ disappeared and a new signal at $3.6 \mathrm{ppm}$ appeared. The $3.6 \mathrm{ppm}$ resonance was tentatively ascribed to a $-\mathrm{RCH}_{2} \mathrm{OH}$ fragment (see Figure S69 in the Supporting Information). Interestingly, a peak at $8.1 \mathrm{ppm}$ was observed, which can be assigned to formate-type fragments (see Figure $9 \mathrm{~A} / \mathrm{D}$ ). The proton NMR findings were further supplemented by ${ }^{13} \mathrm{C}$ NMR, which revealed decreasing intensity of resonances at 67.8 and 95.1-95.2 ppm (see Figure S70 and Figure S71 in the Supporting Information) and consequent appearance of peaks at 64.9, 65.8, 94.9, and $96.7 \mathrm{ppm}$. The former resonances between 64-66 ppm were assigned to the carbons in $-\mathrm{RCH}_{\mathrm{x}} \mathrm{OH}$ fragments (see Figure $9 \mathrm{C} / \mathrm{F}$ ), whereas the later methylenic-carbon resonances ( 94.9 and $96.7 \mathrm{ppm}$ ) can be assigned to hemiacetaltype fragments B and E (Figure 9). These findings were further corroborated by various $2 \mathrm{D}$ NMR measurements. In direct $\mathrm{C}-\mathrm{H}$ correlation (HSOC) spectroscopy, the carbon at $163 \mathrm{ppm}$ displayed a cross peak to protons at $8.1 \mathrm{ppm}$, confirming the existence of the formate group (see Figure S72 in the Supporting Information). Furthermore, a C-H crosspeak between protons at 4.9-5.2 ppm and carbons at 94.9 and $96.7 \mathrm{ppm}$ suggested the existence of hemiacetals of type B and E (Figure 9). The HSOC findings were corroborated by a long-range $\mathrm{C}-\mathrm{H}$ correlation (HMBC) experiment which revealed a cross-peak between a proton at $41 \mathrm{ppm}$ (Hm) and a carbon at $163 \mathrm{ppm}(\mathrm{Ck})$ (see Figure 10) that can be ascribed to fragment D (Figure 9). Thus, the above NMR investigations indicate that the copolyacetal degrades down to parent isohexides or linear-diols. The above hypothesis

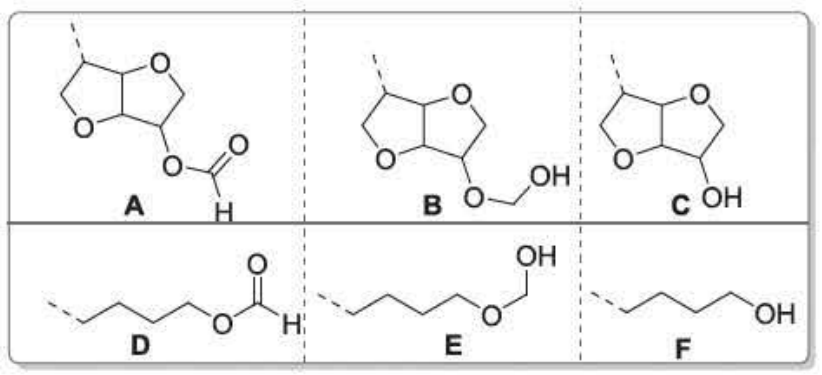

Figure 9. Proposed degradation products based on NMR investigation. 


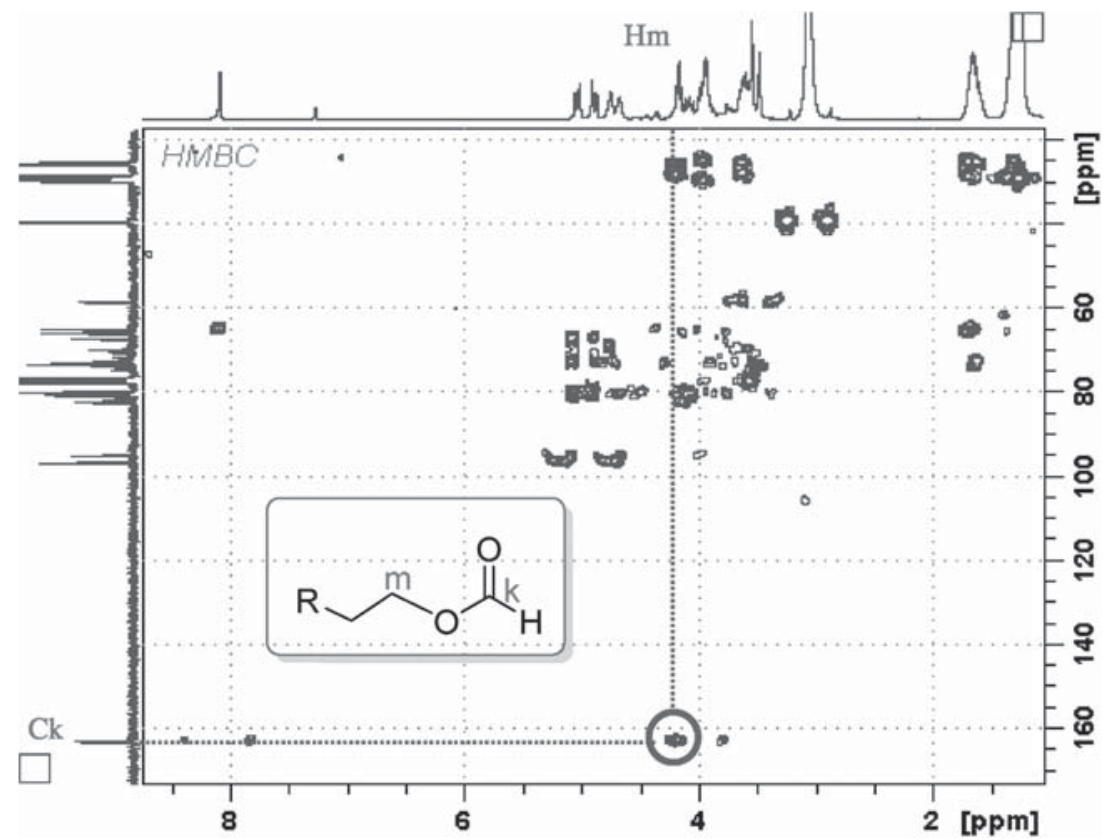

Figure 10. Long-range $\mathrm{C}-\mathrm{H}$ correlation (HMBC) NMR spectrum of acid (MSA) induced degradation of $\mathrm{P}_{3}(4 \mathrm{a}-2 \mathrm{C})$ in $\mathrm{CDCl}_{3}(500 \mathrm{MHz}, 298 \mathrm{~K})$.

was further supported by chromatographic separation of the degradation products. About $200 \mathrm{mg}$ of P3(4a-2c) was dissolved in $20 \mathrm{~mL}$ of chloroform and acidified by adding $1 \mathrm{~mL}$ of hydrochloric acid ( $1 \mathrm{~m}$ in dioxane). After $24 \mathrm{~h}$, volatiles were evaporated to obtain the residue, which displayed the presence of acetal resonances. In order to further degrade the polyacetals, $0.5 \mathrm{~mL}$ of hydrochloric acid $(1 \mathrm{M}$ in dioxane) was added and the copolymer was allowed to degrade for the next $24 \mathrm{~h}$. Volatiles were evaporated and the residue was subjected to column chromatography. The first fraction (ethyl acetate:pet-ether, 40:60) revealed the presence of 1,12-dodecanediol (see Figure S73 and S74 in the Supporting Information) whereas a change of polarity (dichloromethane:methanol, 80:20) was necessary to flush out the second fraction. The proton NMR of this fraction suggested the presence of isomannide. The existence of isomannide was confirmed by comparing the ${ }^{1} \mathrm{H}$ NMR spectrum of commercially available isomannide and the one obtained after column chromatographic separation (see Figure S75 and S76 in the Supporting Information). However, the formats acetal/hemiacetals could not be isolated. It is most likely that these meta-stable fragments degrade to low boiling entities that evaporate along with the solvent before loading on the column or convert to the parent diols.

\section{Conclusions}

In summary, acid catalyzed acetal metathesis copolymerization (AMCP) of isohexide-diacetals with linear, plant oil derived long-chain diacetals has been reported here. A reduced intensity of the methoxy-protons and corresponding carbon indicated the formation of the desired copolyacetals. The proton NMR findings were corroborated by 2D NMR (NOESY, HSOC, and HMBC), which established the correlation between the isohexide-segment and the linear aliphatic segment. Furthermore, ${ }^{1} \mathrm{H}$ NMR results indicated that the stereochemistry of the isohexide-diacetals $4 \mathbf{a}-\mathbf{c}$ was most likely retained during the copolymerization. The copolymer molecular weight was found to be in the range 8000-12 300 (by NMR, and 2000-10 700 $\mathrm{g} \mathrm{mol}^{-1}$ by GPC) $\mathrm{g} \mathrm{mol}^{-1}$. Typically, the $T_{m}$ of the copolyacetals was lower than the parent isohexide-polyacetals. This is partly due to the incorporation of flexible aliphatic segments in the parent isohexide-polyacetals. The copolyacetals P8(4b-2c), P13(4c-2c), P14(4c-2d), and P15(4c-2e) displayed a single melting transition, indicating the presence of either perfectly alternating copolymer or one type of crystal form in the copolymers. It was observed that with an increasing carbon chain length of long chain diacetals (2a-e) the melting temperature of the resultant copolyacetals increased. The copolyacetals were found to be thermally stable up to $325^{\circ} \mathrm{C}$. TGA revealed that the copolyacetals derived from long-chain diacetals were more stable compared to the copolyacetals derived from short-chain diacetals.

The biocompatibility of the copolyacetals was determined by subjecting them to various types of degradation. Acid induced time resolved molecular weight degradation investigations using GPC indicated slower degradation for long-chain copolyacetals compared to their short-chain counterparts. Unlike their parent isohexide-polyacetals, hydrolytic degradation investigations revealed that the copolyacetals were relatively stable in acidic media over a period of $15 \mathrm{~d}$, with only $30 \%$ weight loss in $9 \mathrm{M} \mathrm{HCl}$ solution. Thus, the rate of degradation of the copolyacetals was found to be much slower than the parent isohexide-polyacetal homopolymers. This reduced rate of degradation can be attributed to incorporation of hydrophobic long chain segments in the copolyacetals. An in situ degradation investigation (based on 1-2D NMR) suggested the formation of formates, hemiacetals, and diols as degradation products. This was further corroborated by column chromatographic isolation of the parent diols. These findings imply that the properties of the copolyacetals can be tuned to suit a particular application. Thus, the present strategy provides an additional handle to control the rate of degradation by choosing the 
right combination of isohexide-diacetal and linear-diacetal monomers.

\section{Experimental Section}

\subsection{General Methods and Materials}

Manipulations involving moisture sensitive compounds were carried out under an inert gas atmosphere using standard Schlenk techniques or a glove box. Tetrahydrofuran was distilled from sodium/benzophenone under inert conditions. All other solvents were used as received without further purification. Isomannide, isosorbide, 1,12-dodecanediol, sodium hydride, sodium methoxide, and deuterated chloroform were purchased from Sigma Aldrich and used without further purification. 1,6-Hexanediol and 1,8-octanediol were purchased from Alfa Aesar and used without further purification. Chloromethyl methyl ether, methanesulfonic acid, p-Toluenesulfonic acid monohydrate, dimethoxymethane, diethyl azodicarboxylate, triphenyl phosphine, benzoic acid, and hydrochloric acid (4 $\mathrm{m}$ in dioxane) were purchased from Spectrochem Pvt. Ltd. and used without further purification. Isoidide was prepared from isomannide using a reported procedure. ${ }^{[34]}$ NMR spectra were recorded on Bruker Avance 200, 400, and 500 instruments. Chemical shifts were referenced to external reference TMS $\left({ }^{1} \mathrm{H}\right.$ and $\left.{ }^{13} \mathrm{C}\right)$. Coupling constants are given here as absolute values. Mass spectra were recorded on a Thermo scientific Q-Exactive mass spectrometer, with a Hypersil gold C18 column $(150 \times 4.6 \mathrm{~mm}$ diameter, $8 \mu \mathrm{m}$ particle size). The mobile phase used was $90 \%$ methanol + $10 \%$ water $+0.1 \%$ formic acid. Differential scanning colorimetric (DSC) analysis was carried out on a DSC 0-100 from TA Instruments with a heating and cooling rate of $10 \mathrm{~K} \mathrm{~min}^{-1}$. Thermogravimetric analysis (TGA) was carried out on a TA Instruments TGA 05000 under a nitrogen atmosphere. Elemental analysis was completed on a Flash EA 1112 series. MALDI-ToF-MS was performed on an AB SCIEX TOF/TOF ${ }^{\mathrm{TM}} 5800$ and the matrix used was dithranol. GPC measurements were carried out on a Thermo Quest (TO) GPC at $25{ }^{\circ} \mathrm{C}$ using chloroform (Merck, Lichrosolv) as the mobile phase. The analysis was carried out at a flow rate of $1 \mathrm{~mL} \mathrm{~min}{ }^{-1}$ using a set of five $\mu$-styragel HT columns (HT-2 to HT-6) and a refractive index (RI) detector. This column set enabled the determination of a wide range of molecular weights from $10^{2}$ to $10^{6}$. Columns were calibrated with polystyrene standards and the molecular weights reported are with respect to polystyrene standards.

\subsection{Synthesis of 1,6-Hexanediacetal (2a, Scheme 2)}

To a dichloromethane solution (100 mL) of 1, 6-hexanediol (5 g, $\left.42.37 \times 10^{-3} \mathrm{~mol}\right)$ was added dimethoxymethane $(20 \mathrm{~mL}, 223.1 \times$ $\left.10^{-3} \mathrm{~mol}\right)$ and methanesulfonic acid $\left(0.55 \mathrm{~mL}, 8.47 \times 10^{-3} \mathrm{~mol}, 20\right.$ $\mathrm{mol} \%)$, and the mixture was stirred for $24 \mathrm{~h}$ at room temperature.

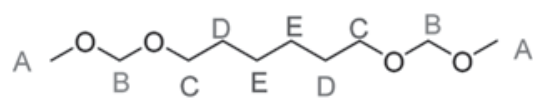

Scheme 2. 1,6-Hexanediacetal.<smiles>COCOCOCCPCCPC(F)COCOCOC</smiles>

- Scheme 3. 1,8-Octanediacetal.

Subsequently, the reaction was quenched by adding ammonium hydroxide solution ( $0.55 \mathrm{~mL}, 25 \%$ solution), followed by washing with saturated sodium chloride solution $(50 \mathrm{~mL})$. The aqueous phase was extracted with ethyl acetate $(3 \times 50 \mathrm{~mL})$ and the combined organic phase was dried over $\mathrm{MgSO}_{4}$, filtered, and the filtrate evaporated to obtain a colorless oily liquid. Purification by column chromatography (hexane:ethyl acetate 90:10) yielded 4.0 $\mathrm{g}(46 \%)$ of colorless liquid.

${ }^{1} \mathrm{H} \mathrm{NMR}\left(400 \mathrm{MHz}, \mathrm{CDCl}_{3}, 298 \mathrm{~K}\right): \delta=4.59\left(\mathrm{~s}, 4 \mathrm{H}_{\mathrm{B}}\right), 3.50(\mathrm{t}$, $\left.J_{\mathrm{H}-\mathrm{H}}=6.6 \mathrm{~Hz}, 4 \mathrm{H}_{\mathrm{C}}\right), 3.34\left(\mathrm{~s}, 6 \mathrm{H}_{\mathrm{A}}\right), 1.64-1.53\left(\mathrm{~m}, 4 \mathrm{H}_{\mathrm{D}}\right), 1.43-1.33$ $\left(\mathrm{m}, 4 \mathrm{H}_{\mathrm{E}}\right) \cdot{ }^{13} \mathrm{C} \mathrm{NMR}\left(100 \mathrm{MHz}, \mathrm{CDCl}_{3}, 298 \mathrm{~K}\right): \delta=96.6\left(\mathrm{~s}, \mathrm{C}_{\mathrm{B}}\right)$, $67.9\left(\mathrm{~s}, \mathrm{C}_{\mathrm{C}}\right.$ ), $55.3\left(\mathrm{~s}, \mathrm{C}_{\mathrm{A}}\right), 29.9\left(\mathrm{~s}, \mathrm{C}_{\mathrm{D}}\right), 26.2$ (s, $\mathrm{C}_{\mathrm{E}}$ ). ESI-MS (+ve mode) $m / z=229.14[\mathrm{M}+\mathrm{Na}]^{+}$. Elemental analysis (\%) Calcd. for $\mathrm{C}_{10} \mathrm{H}_{22} \mathrm{O}_{4}$ : C 58.23, $\mathrm{H}$ 10.75; Found: C 58.61, H 10.93 .

\subsection{Synthesis of 1,8 -Octanediacetal ( $2 b$, Scheme 3 )}

Dimethoxymethane $\left(20 \mathrm{~mL}, 223.1 \times 10^{-3} \mathrm{~mol}\right)$ and methanesulfonic acid $\left(0.44 \mathrm{~mL}, 6.84 \times 10^{-3} \mathrm{~mol}, 20 \mathrm{~mol} \%\right)$ were added to a dichloromethane solution $(100 \mathrm{~mL})$ of 1,8-octanediol $(5 \mathrm{~g}$, $34.19 \times 10^{-3} \mathrm{~mol}$ ) and the mixture was stirred for $24 \mathrm{~h}$ at room temperature to give a clear solution. Subsequently, the reaction was quenched by adding ammonium hydroxide solution $(0.44 \mathrm{~mL}$, $25 \%$ solution) followed by washing with saturated sodium chloride solution $(50 \mathrm{~mL})$. The aqueous phase was extracted with ethyl acetate $(3 \times 50 \mathrm{~mL})$ and the combined organic phase was dried over $\mathrm{MgSO}_{4}$, filtered, and the filtrate evaporated to obtain a colorless oily liquid. Purification by column chromatography (hexane:ethyl acetate $90: 10)$ yielded $4.6 \mathrm{~g}(57 \%)$ of liquid product 2b. ${ }^{1} \mathrm{H}$ NMR $\left(500 \mathrm{MHz}, \mathrm{CDCl}_{3}, 298 \mathrm{~K}\right): \delta=4.54\left(\mathrm{~s}, 4 \mathrm{H}_{\mathrm{B}}\right), 3.44\left(\mathrm{t}, J_{\mathrm{H}-\mathrm{H}}=\right.$ $\left.6.5 \mathrm{~Hz}, 4 \mathrm{H}_{\mathrm{C}}\right), 3.28\left(\mathrm{~s}, 6 \mathrm{H}_{\mathrm{A}}\right), 1.59-1.45\left(\mathrm{~m}, 4 \mathrm{H}_{\mathrm{D}}\right), 1.36-1.23\left(\mathrm{~m}, 8 \mathrm{H}_{\mathrm{E}}+_{\mathrm{F}}\right)$. ${ }^{13} \mathrm{C} \mathrm{NMR}\left(100 \mathrm{MHz}, \mathrm{CDCl}_{3}, 298 \mathrm{~K}\right): \delta=96.5\left(\mathrm{~s}, \mathrm{C}_{\mathrm{B}}\right), 67.9\left(\mathrm{~s}, \mathrm{C}_{\mathrm{C}}\right), 55.1$ (s, $\left.C_{A}\right), 29.8\left(s, C_{D}\right), 29.5\left(s, C_{E}\right), 26.3\left(s, C_{F}\right)$. ESI-MS (+ve mode) $m / z$ $=257.17[\mathrm{M}+\mathrm{Na}]^{+}$. Elemental analysis (\%) Calcd. for $\mathrm{C}_{12} \mathrm{H}_{26} \mathrm{O}_{4}: \mathrm{C}$ 61.51, H 11.18; Found: C 61.99, H 11.51.

\subsection{Acetal Metathesis Copolymerization (AMCP)}

The copolyacetals were prepared in a $50 \mathrm{~mL}$ Schlenk tube equipped with an overhead mechanical stirrer, heating arrangement, and vacuum line. Isohexide-diacetals and linear-diacetals were transferred to the Schlenk tube and p-toluenesulfonic acid was added under positive argon flow. The copolymerization was started by heating the monomer mixture (neat monomers) at $60{ }^{\circ} \mathrm{C}$, which was raised to $90^{\circ} \mathrm{C}$ over a period of $1 \mathrm{~h}$. During the initial $30 \mathrm{~min}$, the reaction vessel was shortly evacuated every $3 \mathrm{~min}$ to remove dimethoxymethane. Note that over evacuation might lead to the loss of short-chain diacetals such as $\mathbf{2 a}$ and $\mathbf{2} \mathbf{b}$, and might create a stoichiometric imbalance in the system. Finally the copolymer melt was stirred for 6 to $12 \mathrm{~h}$ under 
Table 3. Copolymerization conditions and brief polymerization protocol.

\begin{tabular}{|c|c|}
\hline Copolyacetal & Copolymerization Protocol \\
\hline $\mathrm{P} 1(4 \mathrm{a}-2 \mathrm{a})$ & $\begin{array}{l}\text { Temperature was raised from } 60-90^{\circ} \mathrm{C} \text { over a period of } 1 \mathrm{~h} \text {, along } \\
\text { Finally, a constant vacuum of } 0.01 \text { mbar was maintained at } 90^{\circ} \mathrm{C} \\
\text { cous copolymer. }\end{array}$ \\
\hline$P 2(4 a-2 b)$ & $\begin{array}{l}\text { Same as above, except a constant vacuum of } 0.01 \text { mbar was ma } \\
\text { viscous copolymer. }\end{array}$ \\
\hline P3(4a-2c) & $\begin{array}{l}\text { Temperature was raised from } 60-110^{\circ} \mathrm{C} \text { over a period of } 1 \mathrm{~h} \text {, alo } \\
\text { Finally, a constant vacuum of } 0.01 \text { mbar was maintained at } 110 \\
\text { copolymer mass. }\end{array}$ \\
\hline P4(4a-2d) & Same as $\mathbf{P 1} \mathbf{( 4 a - 2 a )}$, except that a solid copolymer was obtained. \\
\hline P5(4a-2e) & Same as $\mathbf{P} \mathbf{4}(\mathbf{4 a - 2} \mathrm{d})$. \\
\hline $\mathrm{P} 6(4 \mathrm{~b}-2 \mathrm{a})$ & Same as $\mathbf{P} \mathbf{1}(\mathbf{4} \mathbf{a}-\mathbf{2} \mathbf{a})$. \\
\hline P7(4b-2b) & Same as $\mathbf{P} \mathbf{1}(\mathbf{4 a - 2 a})$. \\
\hline P8(4b-2c) & Same as $\mathbf{P} \mathbf{1}(\mathbf{4 a - 2 a})$, except that a solid copolymer was obtained. \\
\hline$P 9(4 b-2 d)$ & Same as $\mathbf{P 1} \mathbf{1} \mathbf{4 a - 2 a})$, except that a solid copolymer was obtained. \\
\hline P10(4b-2e) & Same as $\mathbf{P 1}(\mathbf{4 a - 2 a})$, except that a solid copolymer was obtained. \\
\hline P11(4c-2a) & Same as $\mathbf{P 1} \mathbf{1} \mathbf{4 a - 2 a})$. \\
\hline P12(4c-2b) & Same as $\mathbf{P} \mathbf{1}(\mathbf{4 a - 2} \mathbf{a})$. \\
\hline $\mathrm{P} 13(4 \mathrm{c}-2 \mathrm{c})$ & Same as $\mathbf{P 1}(\mathbf{4 a - 2 a})$, except that a solid copolymer was obtained. \\
\hline P14(4c-2d) & 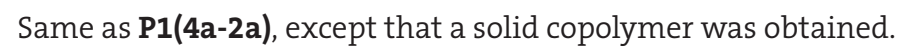 \\
\hline $\mathrm{P} 15(4 c-2 e)$ & 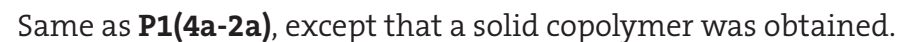 \\
\hline
\end{tabular}

reduced pressure (0.01 mbar), and the copolymer was recovered. The thus obtained copolymer was dissolved in chloroform and precipitated by pouring in methanol. The resultant solid/semisolid material was dried in a vacuum. The quantitative details and reaction parameters are summarized in Table 2 and Table 3 respectively. Representative analytical data for the herein synthesized copolyacetals is supplied in the following section and the detailed spectra can be found in the Supporting Information.

\subsection{1. $\mathrm{P} 1(4 \mathrm{a}-2 \mathrm{a})$ (Scheme 4)}

${ }^{1} \mathrm{H}$ NMR (200 MHz, $\mathrm{CDCl}_{3}, 298 \mathrm{~K}$ ): $\delta=4.82$ (br., s, $\mathrm{H}_{\mathrm{B}}$ ), $4.53\left(\mathrm{~m}, \mathrm{H}_{\mathrm{E}}\right.$ ), $4.28\left(\mathrm{~m}, \mathrm{H}_{\mathrm{D}}\right.$ ), 4.00 (br. s, $\mathrm{H}_{\mathrm{C}}$ ), 3.78 (br., s, $\mathrm{H}_{\mathrm{C}}$ ), 3.64 (t, $J_{\mathrm{H}-\mathrm{H}}=7.7 \mathrm{~Hz}$, $\mathrm{H}_{\mathrm{F}}$ ), 1.61 (br., s, $\mathrm{H}_{\mathrm{G}}$ ), 1.36 (br., s, $\mathrm{H}_{\mathrm{H}}$ ).

\subsubsection{P2(4a-2b) (Scheme 5)}

${ }^{1} \mathrm{H}$ NMR (500 MHz, $\left.\mathrm{CDCl}_{3}, 298 \mathrm{~K}\right): \delta=4.82-4.61\left(\mathrm{~m}, \mathrm{H}_{\mathrm{B}}\right.$ ), 4.53 (br., $\mathrm{s}$, $\mathrm{H}_{\mathrm{E}}$ ), 4.27 (br., s, $\mathrm{H}_{\mathrm{D}}$ ), 4.00 (br., s, $\mathrm{H}_{\mathrm{C}}$ ), 3.63 (br., s, $\mathrm{H}_{\mathrm{C}}$ ), 3.47 (br., s, $\mathrm{H}_{\mathrm{F}}$ ), 1.53 (br., s, $\mathrm{H}_{\mathrm{G}}$ ), 1.28 (br., s, $\mathrm{H}_{\mathrm{H}}$ ). ${ }^{13} \mathrm{C}$ NMR (125 MHz, CDCl, $298 \mathrm{~K}$ ): $\delta=95.3-95.0$ (br., s, $\left.\mathrm{C}_{\mathrm{B}}\right), 80.8\left(\mathrm{~s}, \mathrm{C}_{\mathrm{E}}\right), 78.1\left(\mathrm{~s}, \mathrm{C}_{\mathrm{D}}\right), 75.3\left(\mathrm{~s}, \mathrm{C}_{\mathrm{C}}\right), 71.1(\mathrm{~s}$, $\left.\mathrm{C}_{\mathrm{C}}\right), 67.9\left(\mathrm{~s}, \mathrm{C}_{\mathrm{F}}\right), 29.8-29.5\left(\mathrm{~m}, \mathrm{C}_{\mathrm{G}}\right), 26.3$ (br., s, $\left.\mathrm{C}_{\mathrm{H}}\right)$.

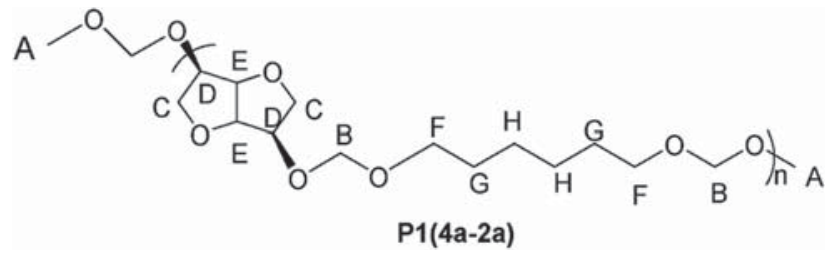

Scheme 4. Copolyacetal $\mathrm{P}_{1}(4 \mathrm{a}-2 \mathrm{a})$.

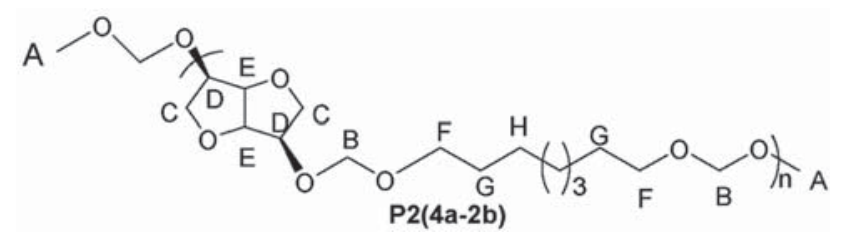

Scheme 5. Copolyacetal P2(4a-2b).

\subsubsection{P3(4a-2c) (Scheme 6)}

${ }^{1} \mathrm{H}$ NMR (500 MHz, $\left.\mathrm{CDCl}_{3}, 298 \mathrm{~K}\right): \delta=4.85-4.63\left(\mathrm{~m}, \mathrm{H}_{\mathrm{B}}\right), 4.54(\mathrm{~m}$, $\left.\mathrm{H}_{\mathrm{E}}\right), 4.29\left(\mathrm{~m}, \mathrm{H}_{\mathrm{D}}\right), 4.01\left(\mathrm{~m}, \mathrm{H}_{\mathrm{C}}\right), 3.65\left(\mathrm{~m}, \mathrm{H}_{\mathrm{C}}\right), 3.48\left(\mathrm{t}, J_{\mathrm{H}-\mathrm{H}}=6.65 \mathrm{~Hz}\right.$, HF), 1.54 (br., s, HG), 1.24 (br., s, HH). ${ }^{13} \mathrm{C}$ NMR (125 MHz, CDCl $298 \mathrm{~K}): \delta=95.4\left(\mathrm{~s}, \mathrm{C}_{\mathrm{B}}\right), 81.8-80.9\left(\mathrm{~s}, \mathrm{C}_{\mathrm{E}}\right), 78.2\left(\mathrm{~s}, \mathrm{C}_{\mathrm{D}}\right), 75.4-74.8\left(\mathrm{~s}, \mathrm{C}_{\mathrm{C}}\right)$, $71.1\left(\mathrm{~s}, \mathrm{C}_{\mathrm{C}}\right), 67.9\left(\mathrm{~s}, \mathrm{C}_{\mathrm{F}}\right), 29.8\left(\mathrm{~s}, \mathrm{C}_{\mathrm{G}}\right), 26.4\left(\mathrm{~s}, \mathrm{C}_{\mathrm{H}}\right)$.

\subsection{4. $\mathrm{P} 4(4 \mathrm{a}-2 \mathrm{~d})$ (Scheme 7)}

${ }^{1} \mathrm{H}$ NMR (200 MHz, $\left.\mathrm{CDCl}_{3}, 298 \mathrm{~K}\right):$ 4.88-4.65 (m, $\mathrm{H}_{\mathrm{B}}$ ), 4.54 (br., s, $\mathrm{H}_{\mathrm{E}}$ ), 4.28 (br., s, $\mathrm{H}_{\mathrm{D}}$ ), 4.04 (br., s, $\mathrm{H}_{\mathrm{C}}$ ), $3.62\left(\mathrm{~m}, \mathrm{H}_{\mathrm{C}}\right.$ ), $3.51\left(\mathrm{~m}, \mathrm{H}_{\mathrm{F}}\right), 1.56$ (br., s, $\mathrm{H}_{\mathrm{G}}$ ), 1.24 (br., s, $\mathrm{H}_{\mathrm{H}}$ ).

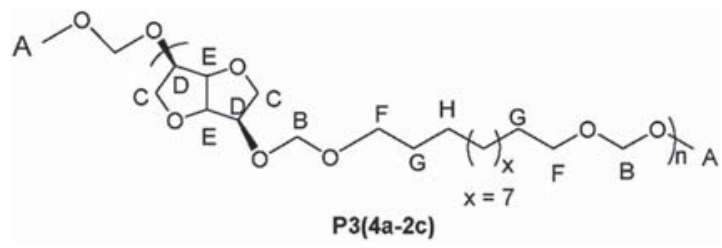

Scheme 6. Copolyacetal P3(4a-2c). 


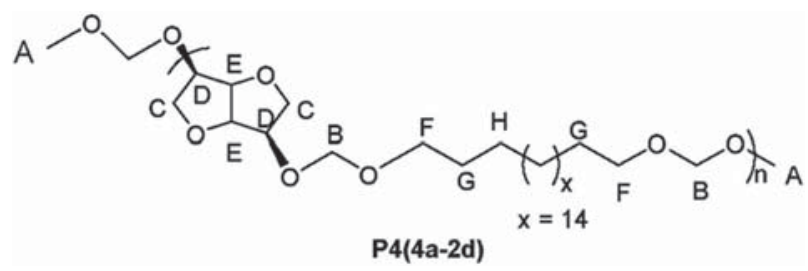

Scheme 7. Copolyacetal $\mathrm{P}_{4}(4 \mathrm{a}-2 \mathrm{~d})$.

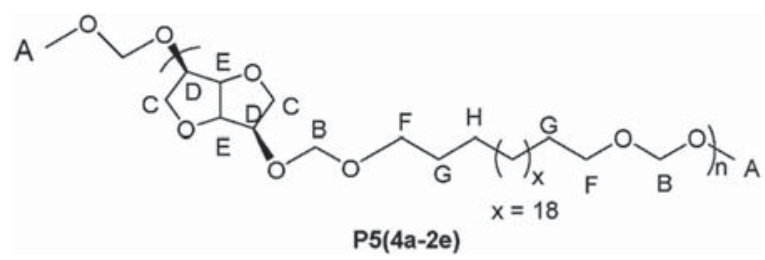

Scheme 8. Copolyacetal P5(4a-2e).

4.4.5. P5(4a-2e) (Scheme 8)

${ }^{1} \mathrm{H}$ NMR (200 MHz, $\left.\mathrm{CDCl}_{3}, 298 \mathrm{~K}\right): \delta=4.87-4.65\left(\mathrm{~m}, \mathrm{H}_{\mathrm{B}}\right), 4.57-4.49$ (m, $\mathrm{H}_{\mathrm{E}}$ ), 4.30 (br., s, $\mathrm{H}_{\mathrm{D}}$ ), 4.03 (br., s, $\mathrm{H}_{\mathrm{C}}$ ), 3.67 (br., s, $\mathrm{H}_{\mathrm{C}}$ ), 3.51 (t, $\left.J_{\mathrm{H}-\mathrm{H}}=6.63 \mathrm{~Hz}, \mathrm{H}_{\mathrm{F}}\right), 1.57$ (br., s, $\left.\mathrm{H}_{\mathrm{G}}\right), 1.24\left(\mathrm{~m}, \mathrm{H}_{\mathrm{H}}\right) .{ }^{13} \mathrm{C} \mathrm{NMR}(50 \mathrm{MHz}$, $\left.\mathrm{CDCl}_{3}, 298 \mathrm{~K}\right): \delta=95.3\left(\mathrm{~s}, \mathrm{C}_{\mathrm{B}}\right), 81.9-80.9\left(\mathrm{~m}, \mathrm{C}_{\mathrm{E}}\right), 78.2\left(\mathrm{~s}, \mathrm{C}_{\mathrm{D}}\right), 74.9(\mathrm{~s}$, $\left.\mathrm{C}_{\mathrm{C}}\right), 71.2\left(\mathrm{~s}, \mathrm{C}_{\mathrm{C}}\right), 68.1\left(\mathrm{~s}, \mathrm{C}_{\mathrm{F}}\right), 29.9\left(\mathrm{~s}, \mathrm{C}_{\mathrm{G}}\right), 26.5\left(\mathrm{~s}, \mathrm{C}_{\mathrm{H}}\right)$.

\subsubsection{P6(4b-2a) (Scheme 9)}

${ }^{1} \mathrm{H}$ NMR (200 MHz, $\left.\mathrm{CDCl}_{3}, 298 \mathrm{~K}\right): \delta=4.85-4.74\left(\mathrm{~m}, \mathrm{H}_{\mathrm{B}}\right), 4.53-4.33$ $\left(\mathrm{m}, \mathrm{H}_{\mathrm{E}}\right), 4.33-4.25\left(\mathrm{~m}, \mathrm{H}_{\mathrm{D}}\right), 4.24-4.08\left(\mathrm{~m}, \mathrm{H}_{\mathrm{E}}{ }_{\mathrm{D}}\right)$, 4.07-3.81 (m, $\left.\mathrm{H}_{\mathrm{C}}\right)$, 3.70-3.41 (m, $\left.\mathrm{H}_{\mathrm{C}^{+}}{ }_{\mathrm{F}}\right), 1.58\left(\mathrm{~m}, \mathrm{H}_{\mathrm{G}}\right), 1.37\left(\mathrm{~m}, \mathrm{H}_{\mathrm{H}}\right)$.

\subsubsection{P7(4b-2b) (Scheme 10)}

${ }^{1} \mathrm{H}$ NMR $\left(200 \mathrm{MHz}, \mathrm{CDCl}_{3}, 298 \mathrm{~K}\right): \delta=4.87-4.53\left(\mathrm{~m}, \mathrm{H}_{\mathrm{B}}\right), 4.53-4.45$ $\left(\mathrm{m}, \mathrm{H}_{\mathrm{E}}\right), 4.44-4.32\left(\mathrm{~m}, \mathrm{H}_{\mathrm{D}}\right), 4.14$ (br., s, $\left.\mathrm{H}_{\mathrm{E}}{ }^{+} \mathrm{D}\right), 3.86$ (br., s, $\mathrm{H}_{\mathrm{C}}$ ), 3.61$3.30\left(\mathrm{~m}, \mathrm{H}_{\mathrm{C}}{ }_{\mathrm{F}}\right), 1.48\left(\mathrm{~m}, \mathrm{H}_{\mathrm{G}}\right), 1.23\left(\mathrm{~m}, \mathrm{H}_{\mathrm{H}}\right) .{ }^{13} \mathrm{C} \mathrm{NMR}\left(50 \mathrm{MHz}, \mathrm{CDCl}_{3}\right.$, $298 \mathrm{~K}): \delta=95.2-94.3\left(\mathrm{~m}, \mathrm{C}_{\mathrm{B}}\right), 88.1\left(\mathrm{~s}, \mathrm{C}_{\mathrm{E}}\right), 86.3\left(\mathrm{~s}, \mathrm{C}_{\mathrm{D}}\right), 81.7-80.6(\mathrm{~m}$, $\left.\mathrm{C}_{\mathrm{E}}\right), 76.3-75.7\left(\mathrm{~m}, \mathrm{C}_{\mathrm{D}}\right), 73.6-73.1\left(\mathrm{~m}, \mathrm{C}_{\mathrm{C}}\right), 69.8\left(\mathrm{~s}, \mathrm{C}_{\mathrm{C}}\right), 68.4-67.8(\mathrm{~m}$, $\left.\mathrm{C}_{\mathrm{F}}\right), 29.7-29.4\left(\mathrm{~m}, \mathrm{C}_{\mathrm{G}}\right), 26.1-25.7\left(\mathrm{~m}, \mathrm{C}_{\mathrm{H}}\right)$.

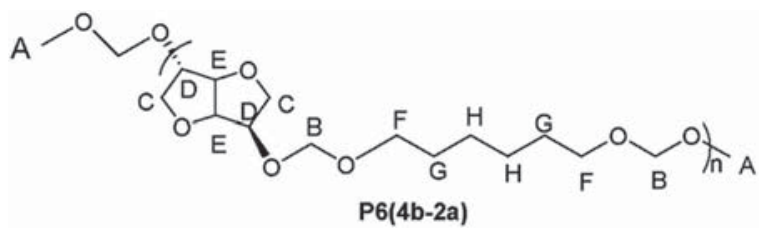

Scheme 9. Copolyacetal P6(4b-2a).

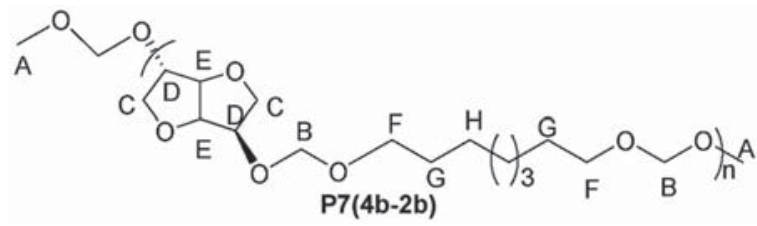

Scheme 10. Copolyacetal P7(4b-2b).

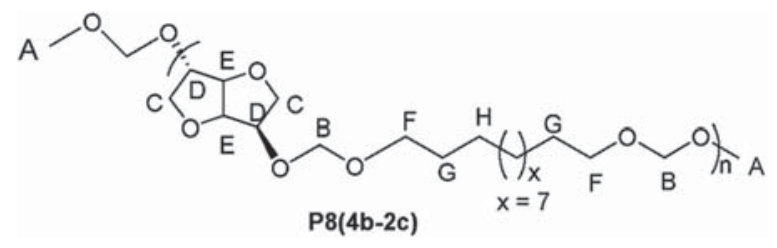

Scheme 11. Copolyacetal P8(4b-2c).

\subsubsection{P8(4b-2c) (Scheme 11)}

${ }^{1} \mathrm{H}$ NMR (200 MHz, $\left.\mathrm{CDCl}_{3,} 298 \mathrm{~K}\right): \delta=4.88-4.60\left(\mathrm{~m}, \mathrm{H}_{\mathrm{B}}\right), 4.61-4.53$ $\left(\mathrm{m}, \mathrm{H}_{\mathrm{E}}\right), 4.48\left(\mathrm{~m}, \mathrm{H}_{\mathrm{D}}\right), 4.34-4.11\left(\mathrm{~m}, \mathrm{H}_{\mathrm{E}}{ }_{\mathrm{D}}\right)$, 4.02-3.79 (m, $\left.\mathrm{H}_{\mathrm{C}}\right), 3.64-$ $3.38\left(\mathrm{~m}, \mathrm{H}_{\mathrm{C}}+_{\mathrm{F}}\right), 1.55$ (br., s, $\left.\mathrm{H}_{\mathrm{G}}\right), 1.24\left(\mathrm{~m}, \mathrm{H}_{\mathrm{H}}\right)$.

\subsection{9. $\mathrm{Pg}(4 \mathrm{~b}-2 \mathrm{~d})$ (Scheme 12)}

${ }^{1} \mathrm{H}$ NMR (500 MHz, CDCl $2,298 \mathrm{~K}$ ): 4.80-4.63 (m, $\mathrm{H}_{\mathrm{B}}$ ), 4.61 (br., s, $\left.\mathrm{H}_{\mathrm{E}}\right)$, 4.53-4.40 (m, $\left.\mathrm{H}_{\mathrm{D}}\right)$, 4.34-4.17 (m, $\left.\mathrm{H}_{\mathrm{E}} \mathrm{t}_{\mathrm{D}}\right)$, 4.09-3.81 (m, $\left.\mathrm{H}_{\mathrm{C}}\right)$, 3.53-3.47 (m, $\mathrm{H}_{\mathrm{C}^{+}}$), 1.56 (br., s, $\mathrm{H}_{\mathrm{G}}$ ), 1.24 (br., s, $\mathrm{H}_{\mathrm{H}}$ ). ${ }^{13} \mathrm{C} \mathrm{NMR}$ $\left(125 \mathrm{MHz}, \mathrm{CDCl}_{3}, 298 \mathrm{~K}\right): \delta=95.4-94.6\left(\mathrm{~m}, \mathrm{C}_{\mathrm{B}}\right), 88.3\left(\mathrm{~s}, \mathrm{C}_{\mathrm{E}}\right), 86.5(\mathrm{~s}$, $\left.\mathrm{C}_{\mathrm{D}}\right), 81.9-80.8\left(\mathrm{~m}, \mathrm{C}_{\mathrm{E}}\right), 76.1-75.9\left(\mathrm{~m}, \mathrm{C}_{\mathrm{D}}\right), 73.9-73.5\left(\mathrm{~m}, \mathrm{C}_{\mathrm{C}}\right), 70.0(\mathrm{~s}$, $\left.\mathrm{C}_{\mathrm{C}}\right), 68.7-68.0\left(\mathrm{~m}, \mathrm{C}_{\mathrm{F}}\right), 30.1-29.6\left(\mathrm{~m}, \mathrm{C}_{\mathrm{G}}\right), 26.4\left(\mathrm{~m}, \mathrm{C}_{\mathrm{H}}\right)$.

\subsubsection{P10(4b-2e) (Scheme 13)}

${ }^{1} \mathrm{H}$ NMR (400 MHz, $\left.\mathrm{CDCl}_{3}, 298 \mathrm{~K}\right)$ : 4.89-4.63 (m, $\mathrm{H}_{\mathrm{B}}+_{\mathrm{E}}$ ), 4.63-4.45 $\left(\mathrm{m}, \mathrm{H}_{\mathrm{D}}\right), 4.41-4.19\left(\mathrm{~m}, \mathrm{H}_{\mathrm{E}}{ }^{+} \mathrm{D}\right), 4.07-3.80\left(\mathrm{~m}, \mathrm{H}_{\mathrm{C}}\right), 3.62\left(\mathrm{t}, J_{\mathrm{H}-\mathrm{H}}=\right.$ $6.5 \mathrm{~Hz}, \mathrm{H}_{\mathrm{c}}$ ), 3.51 (t, $\mathrm{J}_{\mathrm{H}-\mathrm{H}}=6.5 \mathrm{~Hz}, \mathrm{H}_{\mathrm{F}}$ ), 1.57 (br., s, $\mathrm{H}_{\mathrm{G}}$ ), 1.24 (br., s, $\left.\mathrm{H}_{\mathrm{H}}\right) \cdot{ }^{13} \mathrm{C}$ NMR $\left(100 \mathrm{MHz}, \mathrm{CDCl}_{3}, 298 \mathrm{~K}\right): \delta=95.4-94.6\left(\mathrm{~m}, \mathrm{C}_{\mathrm{B}}\right), 88.3$ (br., s, $C_{E}$ ), 86.5 (br., s, $\left.C_{D}\right), 81.8\left(m, C_{E}\right), 75.9\left(s, C_{D}\right), 73.9\left(s, C_{C}\right), 70.2-$ 69.4 (br., m, $C_{C}$ ), 68.1 (s, $C_{F}$ ), 29.9 (br., s, $C_{G}$ ), 26.5(s, $C_{H}$ ).

\subsubsection{P11(4c-2a) (Scheme 14)}

${ }^{1} \mathrm{H}$ NMR (200 MHz, $\left.\mathrm{CDCl}_{3}, 298 \mathrm{~K}\right): \delta=4.85-4.61\left(\mathrm{~m}, \mathrm{H}_{\mathrm{B}}\right), 4.61-4.44$ $\left(\mathrm{m}, \mathrm{H}_{\mathrm{E}}\right), 4.31-4.16\left(\mathrm{~m}, \mathrm{H}_{\mathrm{D}}\right), 3.97-3.67\left(\mathrm{~m}, \mathrm{H}_{\mathrm{C}}\right), 3.60-3.40\left(\mathrm{~m}, \mathrm{H}_{\mathrm{F}}\right)$, 1.57 (br., s, $\mathrm{H}_{\mathrm{G}}$ ), 1.36 (br., s, $\mathrm{H}_{\mathrm{H}}$ ).

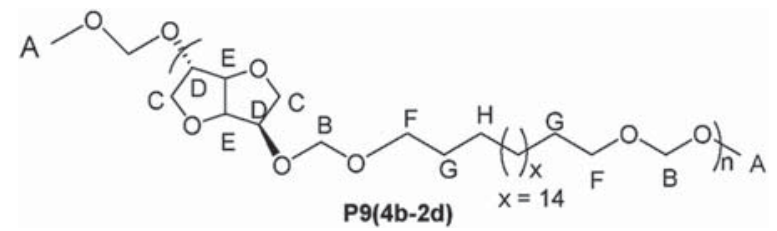

Scheme 12. Copolyacetal P9(4b-2d).

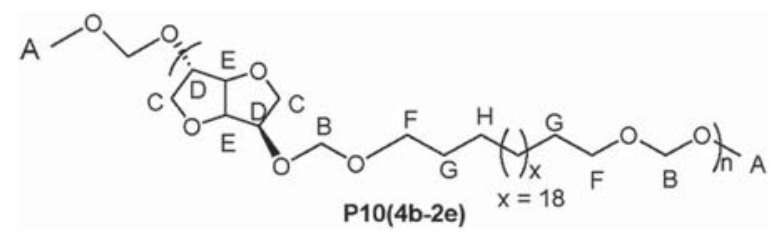

Scheme 13. Copolyacetal P10(4b-2e). 


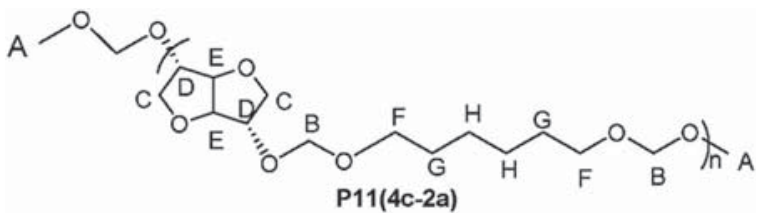

Scheme 14. Copolyacetal P11(4c-2a).

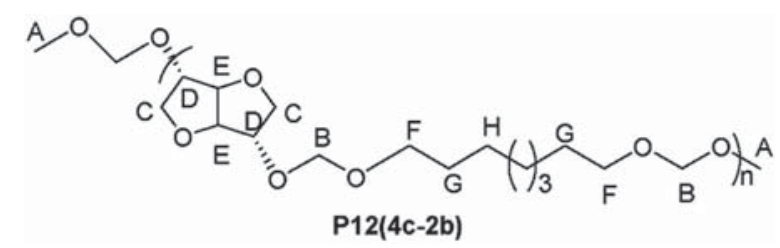

Scheme 15. Copolyacetal P12(4c-2b).

\subsubsection{2. $\mathrm{P} 12(4 \mathrm{c}-2 \mathrm{~b})$ (Scheme 15)}

${ }^{1} \mathrm{H}$ NMR (200 MHz, $\left.\mathrm{CDCl}_{3}, 298 \mathrm{~K}\right): \delta=4.98-4.60\left(\mathrm{~m}, \mathrm{H}_{\mathrm{B}}\right), 4.60-4.39$ $\left(\mathrm{m}, \mathrm{H}_{\mathrm{E}}\right), 4.31-4.16\left(\mathrm{~m}, \mathrm{H}_{\mathrm{D}}\right), 3.95-3.67\left(\mathrm{~m}, \mathrm{H}_{\mathrm{C}}\right), 3.62-3.41\left(\mathrm{~m}, \mathrm{H}_{\mathrm{F}}\right)$, 1.53 (br., s, $\mathrm{H}_{\mathrm{G}}$ ), 1.28 (br., s, $\mathrm{H}_{\mathrm{H}}$ ). ${ }^{13} \mathrm{C}$ NMR $\left(50 \mathrm{MHz}, \mathrm{CDCl}_{3}, 298 \mathrm{~K}\right.$ ): $\delta=95.4-94.6\left(\mathrm{~m}, \mathrm{C}_{\mathrm{B}}\right), 87.6-85.8\left(\mathrm{~m}, \mathrm{C}_{\mathrm{E}}\right), 80.8\left(\mathrm{br} ., \mathrm{s}, \mathrm{C}_{\mathrm{D}}\right), 75.9\left(\mathrm{~s}, \mathrm{C}_{\mathrm{D}}\right)$ 74.6-72.7 (m, $\left.\mathrm{C}_{\mathrm{C}}\right), 68.0\left(\mathrm{~s}, \mathrm{C}_{\mathrm{F}}\right), 29.6\left(\mathrm{~m}, \mathrm{C}_{\mathrm{G}}\right), 26.3\left(\mathrm{~m}, \mathrm{C}_{\mathrm{H}}\right)$.

\subsubsection{P13(4c-2c) (Scheme 16)}

${ }^{1} \mathrm{H}$ NMR $\left(200 \mathrm{MHz}, \mathrm{CDCl}_{3}, 298 \mathrm{~K}\right): \delta=4.86-4.64\left(\mathrm{~m}, \mathrm{H}_{\mathrm{B}}\right), 4.63-4.45$ $\left(\mathrm{m}, \mathrm{H}_{\mathrm{E}}\right), 4.34-4.16\left(\mathrm{~m}, \mathrm{H}_{\mathrm{D}}\right), 3.96-3.71\left(\mathrm{~m}, \mathrm{H}_{\mathrm{C}}\right), 3.55\left(\mathrm{t}, \mathrm{J}_{\mathrm{H}-\mathrm{H}}=6.7 \mathrm{~Hz}\right.$, $\left.\mathrm{H}_{\mathrm{F}}\right), 1.56\left(\mathrm{~m}, \mathrm{H}_{\mathrm{G}}\right), 1.25$ (br., s, $\left.\mathrm{H}_{\mathrm{H}}\right) .{ }^{13} \mathrm{C} \mathrm{NMR}\left(100 \mathrm{MHz}, \mathrm{CDCl}_{3}, 298 \mathrm{~K}\right)$ : $\delta=95.4-94.5\left(\mathrm{~m}, \mathrm{C}_{\mathrm{B}}\right), 87.8-85.8\left(\mathrm{~s}, \mathrm{C}_{\mathrm{E}}\right), 81.8-80.5\left(\mathrm{~s}, \mathrm{C}_{\mathrm{D}}\right), 76.0\left(\mathrm{~s}, \mathrm{C}_{\mathrm{D}}\right)$ 74.6-72.7 (m, $\left.\mathrm{C}_{\mathrm{C}}\right), 68.0\left(\mathrm{~s}, \mathrm{C}_{\mathrm{F}}\right), 29.79\left(\mathrm{t}, \mathrm{J}_{\mathrm{C}-\mathrm{C}}=12.9 \mathrm{~Hz} \mathrm{C}_{\mathrm{G}}\right), 26.4\left(\mathrm{~s}, \mathrm{C}_{\mathrm{H}}\right)$.

\subsubsection{P14(4c-2d) (Scheme 17)}

${ }^{1} \mathrm{H}$ NMR $\left(200 \mathrm{MHz}, \mathrm{CDCl}_{3,}, 298 \mathrm{~K}\right): \delta=4.91-4.62\left(\mathrm{~m}, \mathrm{H}_{\mathrm{B}}\right), 4.62-4.47$ $\left(\mathrm{m}, \mathrm{H}_{\mathrm{E}}\right), 4.36-4.17\left(\mathrm{~m}, \mathrm{H}_{\mathrm{D}}\right), 3.96-3.71\left(\mathrm{~m}, \mathrm{H}_{\mathrm{C}}\right), 3.67-3.41\left(\mathrm{~m}, \mathrm{H}_{\mathrm{F}}\right)$, 1.57 (br., s, $\mathrm{H}_{\mathrm{G}}$ ), 1.25 (m, $\mathrm{H}_{\mathrm{H}}$ ).

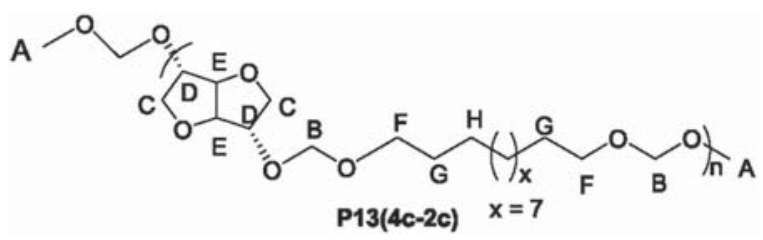

Scheme 16. Copolyacetal $\mathrm{P}_{13}(4 \mathrm{c}-2 \mathrm{c})$.

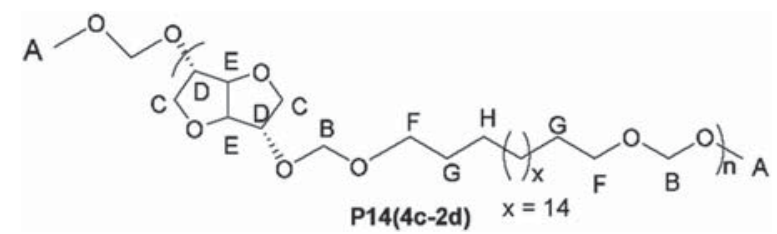

Scheme 17. Copolyacetal P14(4c-2d).

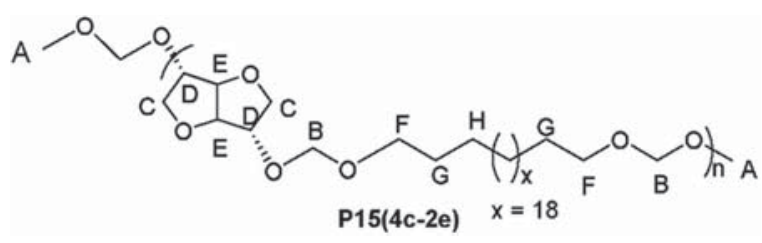

Scheme 18. Copolyacetal P15(4c-2e).

\subsubsection{P15(4c-2e) (Scheme 18)}

${ }^{1} \mathrm{H}$ NMR (200 MHz, CDCl 3 , $\left.298 \mathrm{~K}\right): \delta=4.99-4.63\left(\mathrm{~m}, \mathrm{H}_{\mathrm{B}}\right), 4.63-4.43$ $\left(\mathrm{m}, \mathrm{H}_{\mathrm{E}}\right), 4.39-4.27\left(\mathrm{~m}, \mathrm{H}_{\mathrm{D}}\right), 4.02-3.69\left(\mathrm{~m}, \mathrm{H}_{\mathrm{C}}\right), 3.68-3.40\left(\mathrm{~m}, \mathrm{H}_{\mathrm{F}}\right)$, $1.65\left(\mathrm{~m}, \mathrm{H}_{\mathrm{G}}\right), 1.25\left(\mathrm{~m}, \mathrm{H}_{\mathrm{H}}\right)$.

\subsection{Investigating Copolyacetal Degradation by GPC}

The acid induced degradation of copolyacetals was monitored by GPC. $17 \mathrm{mg}$ of the copolyacetals P3(4a-2c), P5(4a2e), P8(4b-2c), P10(4b-2e), P13(4c-2c), and P15(4c-2e) were accurately weighed and transferred to separate vials. The individual copolyacetals were dissolved in $4 \mathrm{~mL}$ of chloroform and the solution was acidified by adding $0.1 \mathrm{~mL}$ of hydrochloric acid ( $1 \mathrm{~m}$ solution in dioxane). The above solution was allowed to stand for 20, 40, and $60 \mathrm{~min}$. After a suitable time, volatiles were evaporated and the residue was dried on a high vacuum pump. The resultant residue was dissolved in $2 \mathrm{~mL}$ of HPLC grade chloroform and the data was recorded at room temperature against polystyrene standards. The time resolved molecular weight plots of copolyacetals $\mathbf{P 8}(\mathbf{4 b - 2 c})$ and $\mathbf{P} \mathbf{1 0}(\mathbf{4 b}-\mathbf{2 e})$ are presented in Figure 6. The GPC data for the other copolyacetals [P3(4a-2C) and P5(4a-2e); P13(4c-2c) and P15(4c-2e)] are depicted in Figure S64 and Figure S65 in the Supporting Information, respectively.

\subsection{Acid Induced Hydrolytic Degradation}

Approximately 22-24 mg (see Table 4 for more details) of the copolyacetal P15(4c-2e) were weighed and transferred to a DSC crucible lid. The pellets were prepared by melting the copolyacetals in the lid and ejecting the pellet by gentle shaking after cooling to room temperature. The thus prepared pellets were dried in a vacuum for $2 \mathrm{~h}$ and stored under an argon atmosphere. The pellets were suspended in $5 \mathrm{~mL}$ of $\mathrm{HCl}$ solution $(3 \mathrm{M}$ and $9 \mathrm{M}$ ) for $5 \mathrm{~d}$ with gentle stirring. After completing the desired time period, the hydrochloric acid solution was decanted off and the pellets were dried in a vacuum for $12 \mathrm{~h}$ or until constant weight was obtained. A fresh solution of hydrochloric acid ( $3 \mathrm{M}, 9 \mathrm{M}$ ) was added to these pellets and the protocol was repeated after 10 and $15 \mathrm{~d}$. A similar procedure was followed for $\mathrm{pH} 7$ solution. Representative degradation experiments are summarized in Table 4 and in Figure 8. 
Table 4. Hydrolytic degradation of P15(4c-2e) in various media. The pellets were suspended in $5 \mathrm{~mL}$ of a solution of the medium as indicated in the table.

\begin{tabular}{lccccc}
\hline Entry & Initial wt. [mg] & Medium & \% weight loss after 5 d & \% weight loss after 10 d & $\begin{array}{c}\text { \% weight loss after } \\
\text { 15 d }\end{array}$ \\
\hline 1 & 22.0 & $\mathrm{pH}$ & $\mathrm{NA}$ & $\mathrm{NA}$ & 7 \\
2 & 23.6 & $3 \mathrm{M.HCl}$ & 3 & 12 & 15 \\
3 & 23.6 & $9 \mathrm{M} . \mathrm{HCl}$ & 12 & 23 & 30
\end{tabular}

Efforts to prepare a reasonable pellet from the short-chain copolyacetals were not very successful.

\subsection{Total Degradation of Copolyacetals and Isolation of Degradation Products}

The acid induced degradation of copolyacetals was further monitored by ${ }^{1} \mathrm{H}$ and ${ }^{13} \mathrm{C}$ NMR spectroscopy. As a representative of the copolyacetals reported in this manuscript, P3(4a-2c) was chosen. $55 \mathrm{mg}$ of P3(4a-2c) were dissolved in $0.6 \mathrm{~mL}$ of $\mathrm{CDCl}_{3}$ and $0.1 \mathrm{~mL}$ of methanesulfonic acid was added to the NMR tube and the changes were recorded. A time resolved proton NMR spectrum of the copolyacetal is presented in Figures S67-S70 in the Supporting Information.

In an attempt to identify the degradation products, $200 \mathrm{mg}$ of copolyacetal P3(4a-2c) was dissolved in $20 \mathrm{~mL}$ of chloroform and acidified by adding $1 \mathrm{~mL}$ of hydrochloric acid ( $1 \mathrm{~m}$ in dioxane) and the resultant mixture was kept for $24 \mathrm{~h}$. After $24 \mathrm{~h}$, volatiles were evaporated to obtain the residue, which displayed the presence of acetal resonances. In order to further degrade the polyacetals, $0.5 \mathrm{~mL}$ of hydrochloric acid ( $1 \mathrm{~m}$ in dioxane) was added and the copolymer was allowed to degrade for the next $24 \mathrm{~h}$. Volatiles were evaporated and the residue was subjected to column chromatography. The first fraction (ethyl acetate:pet. ether; 40:60) revealed the presence of 1,12-dodecanediol (see Figure S73 and Figure S74 in the Supporting Information) whereas a change of polarity (dichloromethane:methanol; $80: 20)$ was required to flush out the second fraction. The proton NMR spectrum of this fraction suggested the presence of isomannide. The existence of isomannide was confirmed by comparing the ${ }^{1} \mathrm{H}$ NMR spectrum of commercially available isomannide to the one obtained after column chromatographic separation (See Figure S75 and Figure S76 in the Supporting Information).

\section{Supporting Information}

Supporting Information is available from the Wiley Online Library or from the author.

Acknowledgements: Financial support from DST (SR/S1/ IC-60/2012 and SR/S2/RJN-11/2012) is gratefully acknowledged.
CSIR-National Chemical Laboratory and SPIRIT (DCPC) are gratefully acknowledged for additional support. SHC would like to thank the Alexander von Humboldt Foundation for an equipment grant.

Received: February 19, 2016; Published online: April 13, 2016; DOI: $10.1002 /$ macp.201600071

Keywords: copolyacetals; degradable polymers; diacetals; isohexides; renewable polymers

[1] S. Mecking, Angew. Chem. Int. Ed. 2004, 43, 1078.

[2] a) D. R. Dodds, R. A. Gross, Science 2007, 318, 1250; b) U. Biermann, U. Bornscheuer, M. A. R. Meier, J. O. Metzger, Angew. Chem. Int. Ed. 2011, 50, 3854; c) P. Y. Dapsens, C. Mondelli, J. Perez-Ramirez, ACS Catal. 2012, 2, 1487; d) S. Chikkali, S. Mecking, Angew. Chem. Int. Ed. 2012, 51, 5802; e) R. W. Gosselink, S. A. W. Hollak, S. W. Chang, J. van Haveren, K. P. de Jong, J. H. Bitter, D. S. van Es, ChemSusChem 2013, 6, 1576; f) G. Chatel, R. D. Rogers, ACS Sustainable Chem. Eng. 2014, 2, 322.

[3] a) S. Munoz-Guerra, C. Lavilla, C. Japu, A. M. de Ilarduya, Green Chem. 2014, 16, 1716; b) M. Kadraoui, T. Maunoury, Z. Derriche, S. Guillarme, C. Saluzzo, Eur. J. Org. Chem. 2015 , 2015, 441.

[4] P. N. R. Vennestrom, C. M. Osmundsen, C. H. Christensen, E. Taarning, Angew. Chem., Int. Ed. 2011, 50, 10502.

[5] a) A. H. Tullo, Chem. Eng. News 2011, 89, 10; b) A. H. Tullo, Chem. Eng. News 2011, 89, 9; c) M. Singhvi, D. Gokhale, RSC Adv. 2013, 3, 13558; d) T. A. Hottle, M. M. Bilec, A. E. Landis, Polym. Degrad. Stab. 2013, 98, 1898; e) For more details on PLA visit: NatureWorks homepage, http://www.natureworksllc.com/, accessed: 19th Feb. 2016; f) M. N. Somleva, O. P. Peoples, K. D. Snell, Plant Biotechnol. J. 2013, 11, 233; g) For more information about sugarcane derived polyethylene see Baskem homepage, http://www.braskem.com/ site.aspx/green-products-USA, accessed on 19th Feb. 2016.

[6] S. Chikkali, F. Stempfle, S. Mecking, Macromol. Rapid Commun. 2012, 33, 1126.

[7] a) A. G. Pemba, J. A. Flores, S. A. Miller, Green. Chem. 2013, 15,325 ; b) S. A. Miller, A. G. Pemba (University of Florida, USA), US 2014/0024801A1, 2014.

[8] a) P. A. Fokou, M. A. R. Meier, J. Am. Chem. Soc. 2009, 131, 1664; b) B. A. J. Noordover, V. G. van Staalduinen, R. Duchateau, C. E. Koning, R. A. T. M. van Benthem, M. Mak, A. Heise, A. E. Frissen, J. van Haveren, Biomacromolecules 2006, 7, 3406; c) J. Wu, P. Eduard, S. Thiyagarajan, L. Jasinska-Walc, A. Rozanski, C. F. Guerra, B. A. J. Noordover, J. van Haveren, D. S. van Es, C. E. Koning, Macromolecules 2012, 45, 5069.

[9] F. Fenouillot, A. Rousseau, G. Colomines, R. Saint-Loup, J. P. Pascault, Prog. Polym. Sci. 2010, 35, 578. 
[10] H. R. Kricheldorf, Polym. Rev. 1997, 37, 599.

[11] P. Stoss, R. Hemmer, Adv. Carbohydr. Chem. Biochem. 1991, 49, 93.

[12] a) H. Fletcher, R. Goepp, J. Am. Chem. Soc. 1946, 68, 939; b) G. Flche, M. Huchette, Starch/Staerke 1986, 38, 26.

[13] a) H. Fletcher, R. Goepp, J. Am. Chem. Soc. 1945, 67, 1042; b) R. Hockett, H. Fletcher, E. Sheffield, R. Goepp, S. Soltzberg, J. Am. Chem. Soc. 1946, 68, 930.

[14] F. Fenouillot, A. Rousseau, G. Colomines, R. Saint-Loup, J. P. Pascault, Prog. Polym. Sci. 2010, 35, 578 and references therein.

[15] S. Kumar, U. Ramachandran, Tetrahedron 2005, 61, 4141.

[16] S. Guillarme, T. X. M. Nguyen, C. Saluzzo, Tetrahedron: Asymmetry 2008, 19, 1450 .

[17] a) K. Huynh, H. Ibrahim, M. Toffano, G. Vo-Thanh, Tetrahedron: Asymmetry 2010, 21, 1542; b) C. Paolucci, G. Rosini, Tetrahedron: Asymmetry 2007, 18, 2923.

[18] a) E. Muri, B. Abrahim, T. Barros, J. Williamson, O. An- tunes, Mini-Rev. Org. Chem. 2010, 7, 75; b) U. Thadani, R. G. Jacob, Drugs of Today 2008, 44, 925.

[19] a) M. Rose, R. Palkovits, ChemSusChem 2012, 5, 167; b) P. Tundo, F. Arico, G. Gauthier, L. Rossi, A. E. Rosamilia, H. S. Bevinakatti, R. L. Sievert, C. P. Newmann, ChemSusChem 2010, 3, 566 and references therein; c) A. Lavergne, Y. Zhu, V. Molinier, J.-M. Aubry, Colloids Surf. A. 2012, 404, 56; d) G. P. Dillon, J. M. Gaynor, D. Khan, C. G. Carolan, S. A. Ryder, J. F. Marquez, S. Reidy, J. F. Gilmer, Bioorg. Med. Chem. 2010, 18, 1045.

[20] a) D. Braun, M. Bergmann, J. Prakt. Chem. 1992, 334, 298; b) J. Thiem, H. Leuders, Starch/Starke 1984, 36, 170; c) J. Thiem, H. Leuders, Polymer Bull. 1984, 11, 365.

[21] a) J. Wu, P. Eduard, S. Thiyagarajan, J. van Haveren, D. S. van Es, C. E. Koning, M. Lutz, C. F. Guerra, ChemSusChem 2011, 4, 599; b) J. Wu, P. Eduard, S. Thiyagarajan, B. A. J. Noordover, D. S. van Es, C. E. Koning, ChemSusChem 2015, 8, 67 .

[22] a) L. Jasinska, M. Villani, J. Wu, D. van Es, E. Klop, S. Rastogi, C. E. Koning, Macromolecules 2011, 44, 3458; b) A. Wroblewska, A. Zych, S. Thiyagarajan, D. Dudenko, D. van Es, M. R. Hansen, C. Koning, R. Duchateau, L. Jasinska-Walc, Polym. Chem. 2015, 6, 4133.
[23] M. D. Zenner, Y. Xia, J. S. Chen, M. R. Kessler, ChemSusChem 2013, 6, 1182.

[24] a) J. Wu, P. Eduard, L. Jasinska-Walc, A. Rozanski, B. A. J. Noordover, D. S. van Es, C. E. Koning, Macromolecules 2013, 46, 384; b) S. Thiyagarajan, J. Wu, R. J. I. Knoop, J. van Haveren, M. Lutz, D. S. van Es, RSC Adv. 2014, 4, 47937.

[25] J. Wu, P. Eduard, S. Thiyagarajan, L. Jasinska-Walc, A. Rozanski, C. F. Guerra, B. A. J. Noordover, J. van Haveren, D. S. van Es, Macromolecules 2012, 45, 5069.

[26] a) B. S. Rajput, S. R. Gaikwad, S. K. Menon, S. H. Chikkali, Green Chem. 2014, 16, 3810; b) S. Chikkali, B. Rajput (CSIRNCL), WO2014/181358/A2, 2014.

[27] The diacetals were prepared following a method described in our earlier reports, see ref. [6] and ref. [26] for more details.

[28] See Supporting Information for more details.

[29] The molecular weight seems to be low; the GPC-PS standard used for calculating the molecular weight might not be suitable for this type of polymer. A similar observation was made for parent isohexide-polyacetals, wherein the GPC molecular weight was much lower than the NMR molecular weight. Therefore, only GPC molecular weights are reported.

[30] a) S. E. Paramonov, E. M. Bachelder, T. T. Beaudette, S. M. Standley, C. C. Lee, J. Dashe, J. M. J. Frechet, Bioconjugate Chem. 2008, 19, 911; b) Y. Wang, H. Morinaga, A. Sudo, T. Endo, J. Polym. Sci., Part A 2011, 49, 596; c) J. Rickerby, R. Prabhakar, M. Ali, J. Knowles, S. Brocchini, J. Mater. Chem. 2005, 15, 1849.

[31] a) T. W. Greene, P. G. M. Wuts, Protective Groups in Organic Synthesis, Wiley-Interscience, New York 1999, p. 27; b) M. P. Groziak, A. Koohang, J. Org. Chem. 1992, 57, 940.

[32] P. Ortmann, I. Heckler, S. Mecking, Green Chem. 2014, 16, 1816.

[33] For example, packaging will require a relatively stable polymer (over months), while sutures will require a polymer that can degrade within days.

[34] G. de Coster, K. Vandyck, E. van der Eycken, J. van der Eycken, M. Elseviers, H. Roper, Tetrahedron: Asymmetry 2002, 13, 1673. 